\title{
¿Importance of Orography for Greenland Cloud and Melt Response to Atmospheric Blocking 0
}

\author{
L. C. HAHN \\ Physical Oceanography Department, Woods Hole Oceanographic Institution, Woods Hole, Massachusetts, and Section for \\ Meteorology and Oceanography, Department of Geosciences, University of Oslo, Oslo, Norway \\ T. STORELVMO \\ Section for Meteorology and Oceanography, Department of Geosciences, University of Oslo, Oslo, Norway

\section{S. HOFER} \\ School of Geographical Sciences, University of Bristol, Bristol, United Kingdom, and Laboratory of Climatology, \\ Department of Geography, University of Liège, Liège, Belgium

\section{R. PARFITT}

Physical Oceanography Department, Woods Hole Oceanographic Institution, Woods Hole, Massachusetts, and Department of Earth, Ocean and Atmospheric Science, Florida State University, Tallahassee, Florida

\section{C. UMMENHOFER}

Physical Oceanography Department, Woods Hole Oceanographic Institution, Woods Hole, Massachusetts

(Manuscript received 15 July 2019, in final form 19 November 2019)

\begin{abstract}
More frequent high pressure conditions associated with atmospheric blocking episodes over Greenland in recent decades have been suggested to enhance melt through large-scale subsidence and cloud dissipation, which allows more solar radiation to reach the ice sheet surface. Here we investigate mechanisms linking high pressure circulation anomalies to Greenland cloud changes and resulting cloud radiative effects, with a focus on the previously neglected role of topography. Using reanalysis and satellite data in addition to a regional climate model, we show that anticyclonic circulation anomalies over Greenland during recent extreme blocking summers produce cloud changes dependent on orographic lift and descent. The resulting increased cloud cover over northern Greenland promotes surface longwave warming, while reduced cloud cover in southern and marginal Greenland favors surface shortwave warming. Comparison with an idealized model simulation with flattened topography reveals that orographic effects were necessary to produce area-averaged decreasing cloud cover since the mid-1990s and the extreme melt observed in the summer of 2012. This demonstrates a key role for Greenland topography in mediating the cloud and melt response to large-scale circulation variability. These results suggest that future melt will depend on the pattern of circulation anomalies as well as the shape of the Greenland Ice Sheet.
\end{abstract}

D Denotes content that is immediately available upon publication as open access.

Supplemental information related to this paper is available at the Journals Online website: https://doi.org/10.1175/JCLI-D-190527.s1.

Corresponding author: Lily Hahn, lchahn@uw.edu

\section{Introduction}

Recent literature highlights the role of natural variability in atmospheric circulation patterns in promoting Greenland melt. The leading mode of North Atlantic atmospheric circulation variability, the North Atlantic Oscillation (NAO) promotes high pressure conditions over the Greenland Ice Sheet (GrIS) during its negative phase (Hurrell 1995; Hurrell et al. 2003). These high 
pressure atmospheric blocking conditions have driven periods of enhanced melt over the past century (Chylek et al. 2004; Hanna et al. 2013). High pressure conditions are further linked to GrIS warming trends since the mid-1990s (Box et al. 2012; Ding et al. 2014; Fettweis et al. 2013b) and record-breaking melt in recent summers (Hanna et al. 2014; McLeod and Mote 2016; Tedesco et al. 2013, 2016). Having significantly increased since 1981 (Hanna et al. 2016), summertime Greenland blocking is expected to remain an important driver of extreme melt throughout the twentyfirst century (Delhasse et al. 2018; Hahn et al. 2018; Hanna et al. 2018; Hofer et al. 2019). Predictions of Greenland melt therefore depend on understanding the impacts of blocking, with potential global effects on sea level rise (Aschwanden et al. 2019; Fettweis et al. 2013a; Shepherd et al. 2012) and ocean circulation changes (Böning et al. 2016; Oltmanns et al. 2018; Rahmstorf et al. 2015).

Previous work has extensively linked atmospheric blocking to variability, trends, and extremes in Greenland melt. However, questions remain concerning the mechanisms supporting these links. High pressure anticyclonic circulation anomalies during summer may promote Greenland melt by advecting warm air over western Greenland (Fettweis et al. 2011a) or by inducing adiabatic descent and surface warming (Ding et al. 2017). High pressure conditions have additionally been linked to increased melt through cloud changes (Bennartz et al. 2013; Box et al. 2012; Hofer et al. 2017, 2019; Lim et al. 2016; Neff et al. 2014). Recent literature highlights the role of cloud dissipation under summertime blocking conditions, which supports shortwave warming as more incoming solar radiation can reach the ice sheet surface (Box et al. 2012; Hofer et al. 2017; Lim et al. 2016). While these studies suggest a large-scale subsidence response to blocking, the idea that large-scale subsidence explains the vertical velocity and therefore cloud cover response to blocking has not yet been investigated. Furthermore, potential impacts of Greenland topography on the response to blocking remain unexplored.

With maximum elevations more than $3 \mathrm{~km}$ above sea level, the GrIS has been found to promote orographic precipitation by forcing ascent of onshore flow (Chen et al. 1997; Schuenemann et al. 2009). Merz et al. (2014b) further show that modeled precipitation patterns over Greenland are sensitive to the choice of topography. In addition to impacts on precipitation, orographic lift has been implicated in promoting liquid bearing clouds at Summit, Greenland (Edwards-Opperman et al.2018), as back trajectory analysis indicates parcel origins well below Summit elevation. These previously proposed topographic impacts on Greenland precipitation and clouds motivate investigation of orographic effects under blocking conditions.
We also investigate cloud radiative effects (CREs) promoted by cloud changes under blocking conditions. While Box et al. (2012), Lim et al. (2016), and Hofer et al. (2017) identify a shortwave cooling impact of Greenland clouds, others have found a dominant longwave warming impact of Greenland clouds, particularly in regions of higher elevation and surface albedo (Bennartz et al. 2013; Miller et al. 2015; Van Tricht et al. 2016). In this vein, high pressure systems may warm Greenland by supporting northward moisture transport (Neff et al. 2014) and formation of clouds with a net warming impact. More recent analysis using automatic weather station data during the melt season corroborates the regional dependence of cloud impacts: clouds in the accumulation zone promote a dominant longwave warming, while clouds in the ablation zone cause dominant shortwave cooling (Wang et al. 2018, 2019). The regionally dependent influence of Greenland clouds on longwave and shortwave surface radiation motivates analysis of the spatial distribution of CRE under high pressure conditions.

The goals of this study are twofold: 1) to understand links between high pressure anomalies and cloud changes promoting extreme Greenland melt and 2) to analyze the radiative impacts of these cloud changes. We specifically focus on the role of Greenland topography in mediating the effect of the large-scale circulation on regional clouds, with ramifications for surface radiation and extreme melt. Section 2 describes reanalysis and satellite datasets as well as regional climate model experiments used in this study. Circulation and cloud anomalies during high pressure summers are presented and compared with low pressure summers in section 3. Section 4 discusses the radiative impacts of blocking-induced cloud changes, while section 5 provides results from an idealized flattened topography experiment. Further discussion and conclusions are given in section 6.

\section{Data and methods}

We use atmospheric reanalysis, satellite observations, and a regional climate model to investigate the effects of high pressure anomalies on clouds and melt over Greenland. For all datasets, monthly means are used to produce summer [June-August (JJA)] averages.

\section{a. Reanalysis data}

For the period from 1979 to 2015, we primarily use the European Centre for Medium-Range Weather Forecasts interim reanalysis (ERA-Interim; Dee et al. 2011) with $\sim 0.7^{\circ}$ horizontal resolution to examine the large-scale circulation. In a comparison of seven different reanalyses with observations over the Arctic, Lindsay et al. (2014) 
find that ERA-Interim consistently performs best in terms of near-surface air temperature, surface radiative fluxes, precipitation, and wind speed. Our use of ERAInterim is also motivated for consistency with melt and surface radiation data from a regional climate model which has been forced by ERA-Interim at its lateral boundaries, as described below.

We primarily focus on the effects of atmospheric blocking on cloud fraction, although cloud liquid and ice water path are also shown for ERA-Interim. Hofer et al. (2017) find declining cloud cover since the mid-1990s to be strongly correlated with increasing surface shortwave downwelling radiation and surface melt. Strong correlations also exist between cloud fraction and net CRE over Greenland (Wang et al. 2019). Furthermore, Wang et al. (2018) suggest that Greenland surface albedo may play a more important role than cloud properties in determining CRE. Regional variations in surface CRE are closely linked to variations in surface albedo, which strongly modulates the strength of the shortwave CRE. More specifically, clouds over dark surfaces in the ablation zone cause dominant shortwave cooling, while clouds over bright surfaces in the accumulation zone promote dominant longwave warming during melt season. The contribution of additional cloud properties such as liquid and ice water path to Greenland CRE are further discussed in Bennartz et al. (2013), Miller et al. (2015), Van Tricht et al. (2016), and Wang et al. (2019).

\section{b. Satellite observations and validation}

Analysis of ERA-Interim cloud cover allows for direct comparison with the ERA-Interim large-scale circulation over the full 1979-2015 period. However, this and other reanalysis datasets have been found to display considerable cloud biases in the Arctic (Bennartz et al. 2013; Lenaerts et al. 2017; Liu and Key 2016). For this reason, we additionally use cloud fraction and surface radiative fluxes from Edition 4.0 (Ed4) of the Clouds and the Earth's Radiant Energy System (CERES) Energy Balanced and Filled (EBAF) data product. In comparison with ERA-Interim, in which cloud properties are modeled, CERES EBAF has the advantage of incorporating satellite observations of clouds. CERES cloud properties are derived with the CERES-MODIS cloud retrieval algorithm (Minnis et al. 2011), using MODIS Terra satellite data from March 2000 to June 2002 and MODIS Terra and Aqua data beginning in July 2002. Each MODIS pixel is classified as clear or cloudy, and the cloud fraction is determined as the fraction of cloud pixels divided by the total number of pixels within a given CERES $1.0^{\circ}$ gridded region.

The CERES EBAF product also determines hourly energy fluxes using cloud properties derived from the Aqua and Terra satellites, in addition to geostationary satellites. This product spatially interpolates data gaps and adjusts derived fluxes to observed CERES TOA fluxes (Loeb et al. 2018), ultimately yielding monthly surface energy flux terms at $1^{\circ}$ resolution beginning in 2000. The surface albedo in CERES is derived from both clear-sky and partly cloudy footprints, as described in Kato et al. (2018) and Rutan et al. (2009). Providing both clear-sky and all-sky fluxes, CERES EBAF data allows for estimation of Greenland CRE.

CERES EBAF Ed4.0 also contains biases in polar cloud fraction and surface radiative fluxes, particularly in overestimating cloud fraction and longwave downwelling radiation at Summit during polar night (Kato et al. 2018). Wang et al. (2019) compare an earlier version of the product used to produce EBAF data, CERES Synoptic Radiative Fluxes and Clouds Edition 3A, as well as ERAInterim and other reanalyses, with in situ cloud observations from the Integrated Characterization of Energy, Clouds, Atmospheric State, and Precipitation at Summit (ICECAPS). Of these datasets for summers from 2011 to 2013, CERES most closely resembles Summit observations in terms of magnitude and spatial variability of both cloud fraction and liquid water path. Wang et al. (2019) also compare CERES and ERA-Interim with observations from 21 automatic weather stations (AWS) from the Greenland Climate Network (GC-Net) and the Programme for Monitoring of the Greenland Ice Sheet (PROMICE), with rigorous data quality control described in Wang et al. (2018). AWS all-sky radiation measurements are combined with simulated clear-sky radiation to estimate net CRE, which correlates relatively well between AWS observations and both CERES and ERA-Interim. CERES and ERA-Interim also reproduce the "warm center" spatial pattern of net CRE found in AWS data, with net CRE maximizing at Summit (Wang et al. 2019).

These results from AWS and ICECAPS observations complement the findings of Christensen et al. (2016), who present GC-Net ground-based instrument observations from more than 20 stations in comparison with satellite and reanalysis products for 2007-10. Root-mean-square error in annual net surface radiation compared with these stations is slightly smaller for CERES EBAF version 2.7 $\left(1.0 \mathrm{~W} \mathrm{~m}^{-2}\right)$ than ERA-Interim $\left(1.2 \mathrm{~W} \mathrm{~m}^{-2}\right)$, although biases vary by station. While cloud biases exist in both ERA-Interim and CERES EBAF, in situ observations from Christensen et al. (2016) and Wang et al. (2019) indicate that CERES may provide slightly more realistic cloud cover over Greenland.

\section{c. Regional climate model experiments}

We additionally look at the effects of high pressure anomalies and cloud cover changes on Greenland melt and surface energy terms, which are obtained from the 
Modèle Atmosphérique Régional (MAR) version 3.5.2 at 20-km horizontal resolution (Fettweis et al. 2017). The MAR atmospheric model (Gallée and Schayes 1994; Gallée 1995) is coupled to the one-dimensional Soil Ice Snow Vegetation Atmosphere Transfer scheme surface model (De Ridder and Gallée 1998). This uses the CROCUS snow model (Brun et al. 1992) to determine snow-ice-atmosphere interactions and produce surface energy and mass balance terms. The surface albedo is calculated using the CROCUS snow metamorphism laws (Brun et al. 1992), and has been improved in MARv3.5.2 in consideration of bare ice albedo overestimation in previous versions (Fettweis et al. 2017). MAR is forced at the lateral boundaries every $6 \mathrm{~h}$ with ERA-Interim reanalysis data, including temperature, wind, humidity, and surface pressure fields. While ERAInterim reanalysis data are used to force MAR, MAR's coupling with a multilayered energy balance-based snow model motivates our use of MAR rather than ERAInterim for surface energy and melt terms.

MAR has been developed to match observations of the GrIS and Antarctic surface mass balance components and the atmospheric conditions above the ice sheets (Agosta et al. 2019; Fettweis et al. 2017). It has been rigorously validated against the PROMICE and GC-Net networks of in situ weather observations (temperature, wind speed, radiative fluxes) and against satellite remote sensing data (albedo and melt extent) (Box et al. 2012; Fettweis et al. 2011b, 2017). Additionally, when compared with AVHRR and MODIS observations over the last two decades, MAR successfully reproduces the recent decrease in melt season cloud cover associated with anticyclonic circulation anomalies (Hofer et al. 2017). Hofer et al. (2019) further compare MAR liquid water path (LWP) outputs to observations of cloud LWP over Summit in the interior of the GrIS and demonstrate that MAR captures the LWP dynamics during the melt season. We note, however, that Hofer et al. (2019) use a slightly different MAR version (v3.9.6), and that this point observation might not be representative of the spatiotemporal partitioning between cold, warm, and mixed-phase clouds.

We further use the MAR model to run a flattened topography experiment in comparison with a control topography experiment for the period 1980 to 2017 . For the flattened topography experiment we set the surface height to $0 \mathrm{~m}$ while keeping the extent of the GrIS and tundra unchanged. The model (MARv3.9.3) is run on a $25 \mathrm{~km} \times 25 \mathrm{~km}$ equal-area projection using an integration time step of $150 \mathrm{~s}$.

Previous studies have found that GrIS topography strongly influences the local and large-scale circulation (e.g., Dethloff et al. 2004; Hakuba et al. 2012; Junge et al. 2005; Kristjánsson and McInnes 1999; Kristjánsson et al.

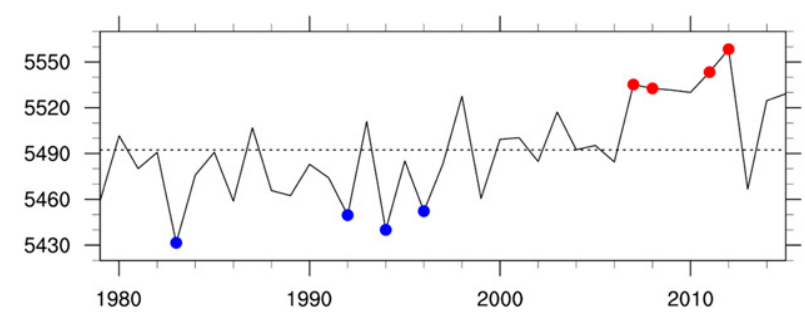

FIG. 1. Time series of summer Greenland blocking index (GBI; m) from ERA-Interim reanalysis, showing high (red dots) and low (blue dots) decile years used in anomaly plots. Dashed line shows average summer GBI for 1979-2015.

2009; Merz et al. 2014a; Petersen et al. 2004; Tsukernik et al. 2007). However, because of the constrained MAR domain, the general circulation regime is imposed upon MAR at its lateral boundaries by the ERA-Interim forcing fields. Geopotential heights over Greenland therefore remain very similar in the flattened topography simulation, as discussed in section 5. With minimized large-scale circulation differences between the flat and control topography experiments, we isolate the role of topography in mediating the cloud and melt response to high pressure anomalies over Greenland.

\section{Cloud response to Greenland blocking}

\section{a. Circulation and cloud response during extreme blocking summers}

To investigate the cloud response to high pressure conditions over Greenland, we first calculate anomalies during extreme Greenland blocking index (GBI) summers. As a measure of circulation changes specific to the Greenland ice sheet, the summer GBI correlates more strongly to Greenland summer temperatures and runoff than the NAO index (Hanna et al. 2013). The summer GBI is defined as the 500-mb geopotential height, areaaveraged for $60^{\circ}-80^{\circ} \mathrm{N}$ and $20^{\circ}-80^{\circ} \mathrm{W}$ and time-averaged for the summer season (Hanna et al. 2013). We therefore use the term "blocking" in this study to refer to anomalous high pressure conditions over Greenland, rather than identifying individual blocking events. By indexing with the summer GBI, we adopt the time- and areaintegrated approach used in previous literature (e.g., Hanna et al. 2013; Hofer et al. 2017; Tedesco et al. 2016). We define high GBI summers (shown with red dots in Fig. 1) as top decile GBI summers for the period 19792015, but additionally test the sensitivity of anomalies to this top decile threshold (Figs. S2-S5 in the online supplemental material). For all composite anomaly plots, a two-tailed Student's $t$ test is used at each grid point to determine significance. 
a) Surface height

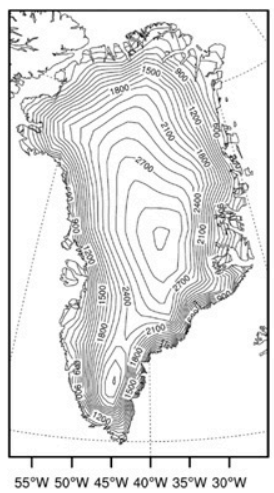

e) $\omega 700$

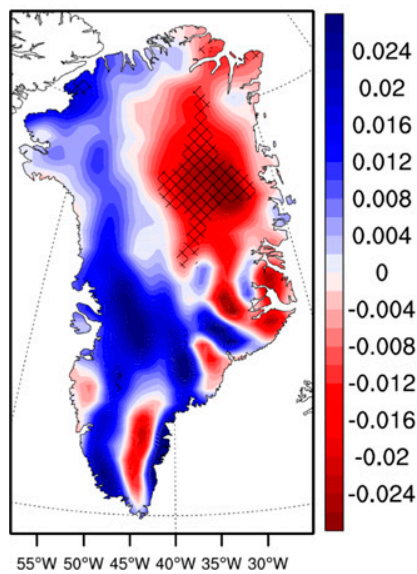

b) Melt

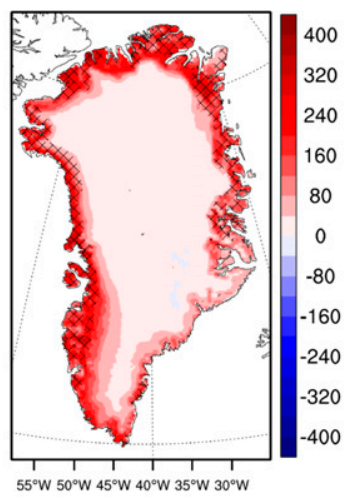

f) Cross-barrier wind

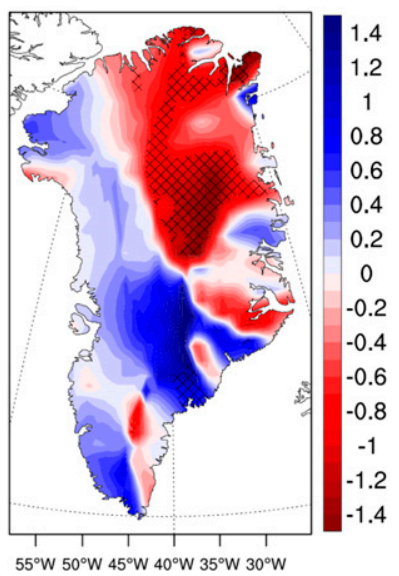

c) Z500 and UV500

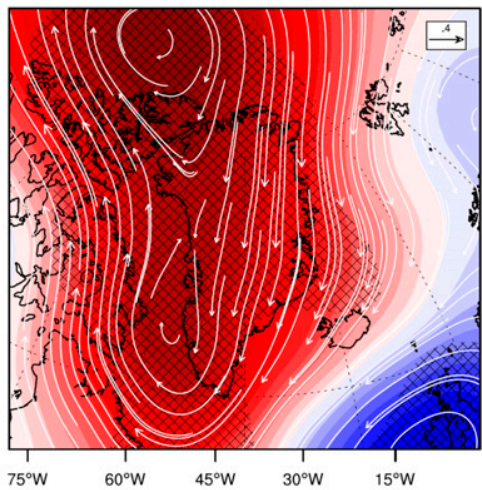

g) Total cloud cover

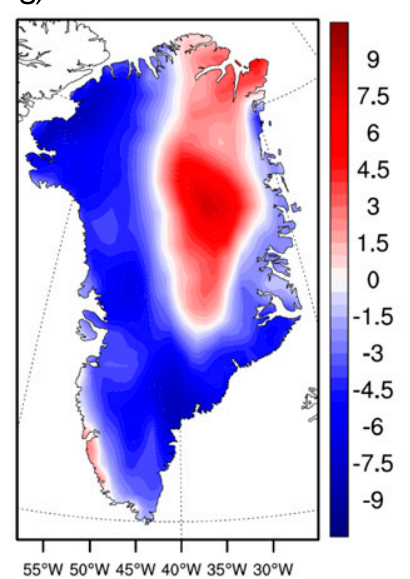

d) $\omega 500$

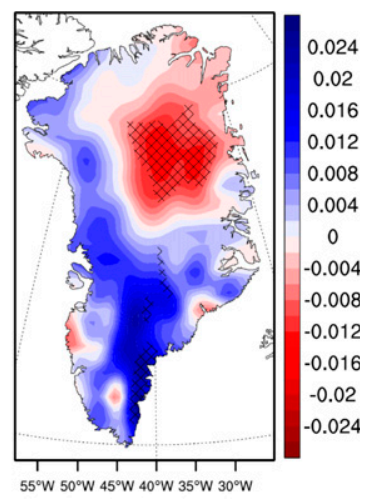

h) Cloud water path

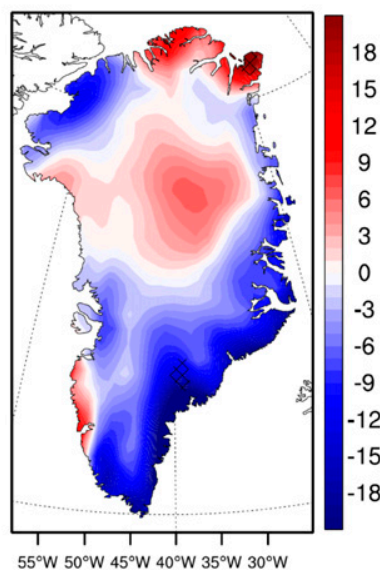

FIG. 2. (a) ERA-Interim time-invariant surface height (m). Anomalies for high decile GBI summers compared to 1979-2015 period from MAR [in (b)] and ERA-Interim [in (c)-(h)] for (b) melt (mm water equivalent month ${ }^{-1}$ ); (c) 500-mb geopotential height (Z500; contours; m) and 500-mb wind (UV500; vectors; $\mathrm{m} \mathrm{s}^{-1}$ ); (d) 500- and (e) 700-mb vertical velocity $\left(\omega 500, \omega 700 ; \mathrm{Pa} \mathrm{s}^{-1}\right)$, where negative values indicate upward anomalies; (f) cross-barrier wind $\left(\mathrm{m} \mathrm{s}^{-1}\right.$ ) vertically integrated from 600 to $1000 \mathrm{mb}$; (g) total cloud cover (\%); and (h) total cloud water path $\left(\mathrm{g} \mathrm{m}^{-2}\right)$. Stippling indicates anomalies significant at the $95 \%$ confidence level for high GBI summers compared to $1979-2015$ conditions.

Greenland surface height and composite anomalies for high GBI summers compared to all summers in the 19792015 period are shown in Fig. 2. During these summers, significant melt anomalies at the ice sheet periphery (Fig. 2b) are driven by high pressure conditions, significant over most of Greenland and surrounding ocean (Fig. 2c). Downward vertical velocity anomalies cover much of the ice sheet during high pressure summers (Fig. 2d). However, an enhanced large-scale subsidence response to anomalous high pressures does not explain the anomalous upward motion observed in northeastern Greenland. At higher levels ( $\omega 300, \omega 400$; figure not shown), vertical velocity anomalies are weaker but qualitatively consistent with $\omega 500$ (Fig. 2d). Interactions between anticyclonic circulation anomalies and Greenland topography (Fig. 2a) appear to drive vertical velocities: anomalous upslope winds correspond to anomalous ascent in northeastern Greenland and anomalous downslope winds to anomalous descent in southern Greenland.
To estimate what portion of the vertical velocity response may be explained by orographic effects, we additionally calculate cross-barrier wind anomalies. These are shown in Fig. 2f, where cross-barrier winds correspond with upward (downward) vertical velocity anomalies in northern (southern) Greenland. To calculate the cross-barrier wind, we find the portion of the horizontal wind at each pressure level perpendicular to surface pressure contours. This is determined as the dot product of the horizontal wind with the gradient in surface pressure. We then mask out areas below the surface and sum the result from 600 to $1000 \mathrm{mb}$, weighted by pressure level thickness. Therefore, some features of upslope cross-barrier winds over southeastern Greenland in Fig. $2 \mathrm{f}$ do not propagate to the $500-\mathrm{mb}$ level of vertical velocities in Fig. 2d, but can be seen at lower levels (Fig. 2e). Orographic lift and descent are key drivers of Greenland's vertical velocity response to blocking, and predict the anomalous uplift seen in northern Greenland 
in contrast with the previously proposed mechanism of large-scale subsidence.

Cloud cover anomalies during high pressure summers are shown in Fig. 2g. Upslope flow anomalies align with increased cloud cover in northeastern Greenland, while downslope flow anomalies correspond to reduced cloud cover in southern and western Greenland. Although we also expect factors such as advection-driven moisture and temperature changes to influence Greenland cloud cover patterns, these anomalies suggest an additional role for orographically driven cloud cover changes during high pressure summers. While large-scale subsidence may amplify reduced cloud cover in southern and western Greenland, it does not explain the increased cloud cover in northeastern Greenland, which is supported by anomalous orographic lift.

Adiabatic expansion and cooling during orographic lifting produce lower saturation vapor pressure and increased cloud cover, while adiabatic compression and warming during descent raise the saturation vapor pressure and contribute to cloud dissipation. Total cloud water path (Fig. $2 \mathrm{~h}$ ) is also generally increased in regions of anomalous uplift in northeastern Greenland and decreased in southern and peripheral Greenland, with anomalous downslope wind. The pattern of total cloud water path anomalies is also representative of cloud ice water path anomalies in ERA-Interim, while cloud liquid water path (Fig. S1) shows positive anomalies over much of Greenland.

To test the sensitivity of high pressure summer conditions to the top $10 \%$ threshold, we reproduce anomaly plots for the top $20 \%$ and $30 \%$ of high pressure summers (Figs. S2 and S3). While the strongest anomalies are found during top decile GBI summers, all threshold choices demonstrate a connection between orographic lift and descent and vertical velocity anomalies over Greenland. Anomalous uplift corresponds to increased cloud cover in the northeast, while anomalous descent promotes reduced cloud cover over southern and western Greenland. In agreement with the anomalies for top decile GBI summers, these lower threshold anomalies demonstrate that our results are relatively insensitive to threshold choice. We additionally plot anomalies for the second and third decile of high pressure summers exclusively in Figs. S4 and S5. While the pattern of circulation anomalies varies for each decile, all deciles individually show a role for orographic lift and descent anomalies promoting anomalous vertical velocities, with impacts on total cloud cover and cloud water path.

To compare ERA-Interim and MAR with CERES EBAF cloud cover, we calculate cloud cover anomalies for the same four high pressure summers shown in Fig. 1 (2007, 2008, 2011, 2012), but now compared with the common data period from 2000 to 2015 (Fig. 3). Although
CERES shows stronger cloud cover increases in northern Greenland than MAR or ERA-Interim, all three datasets demonstrate a similar pattern of increased cloud cover in central and northern Greenland and reduced cloud cover in southern Greenland and along the periphery of the ice sheet. These results are consistent with Hofer et al. (2017), who find similar trends in cloud cover between MAR and MODIS Aqua satellite data from 2002 to 2015 and between MAR and AVHRR from 1982 to 2009.

\section{b. Comparison of high and low pressure summers}

Figure 4 depicts $R^{2}$ values for a linear regression of ERA-Interim summer cross-barrier wind and total cloud cover (top) and cloud water path (bottom) from 1979 to 2015. Correlations between cross-barrier wind and total cloud cover and cloud water path are generally stronger in regions with stronger surface height gradients and therefore weaker for central Greenland. In Figs. $4 \mathrm{~b}$ and $4 \mathrm{~d}$ we include only those summers with GBI values above the 1979-2015 average (above the dashed line in Fig. 1). These high pressure summers show stronger correlations between cross-barrier flow and both cloud cover and cloud water path for many regions, suggesting that orographic effects may be particularly important for Greenland clouds during high pressure summers.

To investigate why high pressure summers exhibit stronger links between orographic lift and cloud cover, we compare anomalies during high decile GBI summers with low decile GBI summers, as identified with red and blue points in Fig. 1. Although statistically significant anomalies are not collocated for cloud cover and cross-barrier wind, cloud cover and cross-barrier wind are better aligned under high pressure than low pressure conditions, particularly for northwest Greenland (Figs. 5b,c,i,j).

One potential explanation for the stronger link between orographic effects and cloud cover during high pressure summers relates to the infrequency of atmospheric fronts under these conditions. Here, atmospheric fronts are identified at 12-hourly intervals on the 600-mb pressure level where the normalized product of the isobaric relative vorticity and horizontal temperature gradient exceeds a given threshold [ $F$ diagnostic; see Parfitt et al. $(2016,2017)$ for a full discussion]. The summer frontal frequency is then calculated for each grid box as the fraction of time in summer with an atmospheric front present. While frontal air mass interactions may normally factor into cloud cover anomalies over Greenland, reduced frontal activity during high pressure summers (Fig. 5n) may allow orographic effects to become more dominant, particularly in coastal areas.

Orographic effects may also be stronger during high pressure summers due to increased specific humidity anomalies (Fig. 51). Previous literature has highlighted 
a) ERA-Interim cloud cover

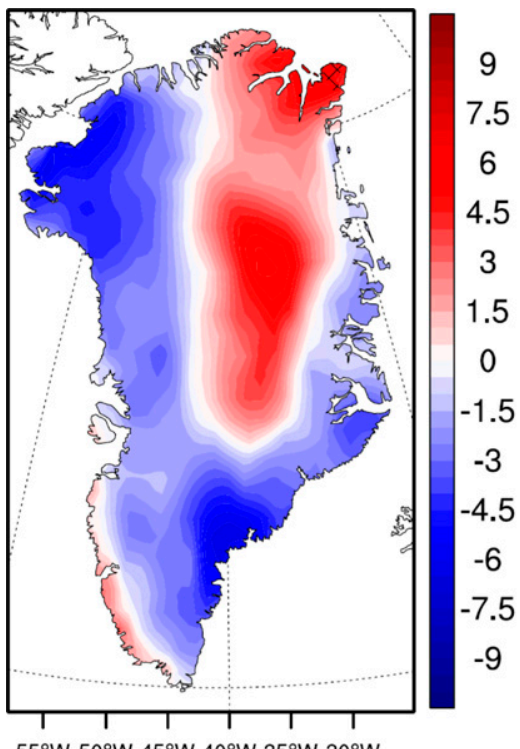

b) MAR cloud cover

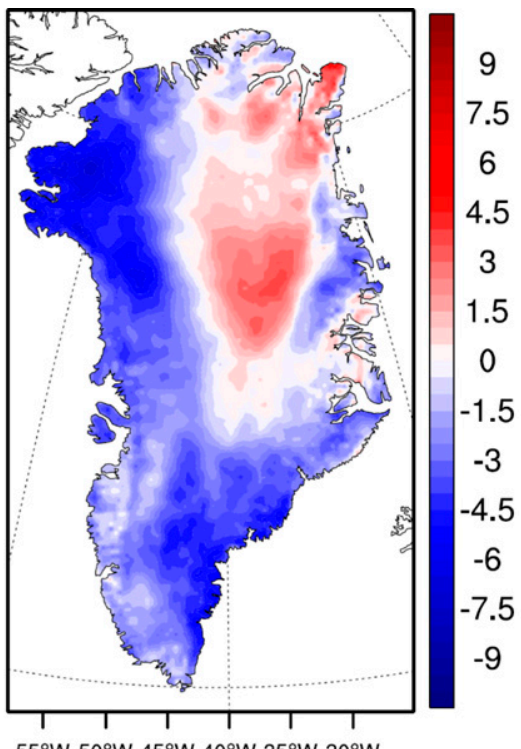

c) CERES cloud cover

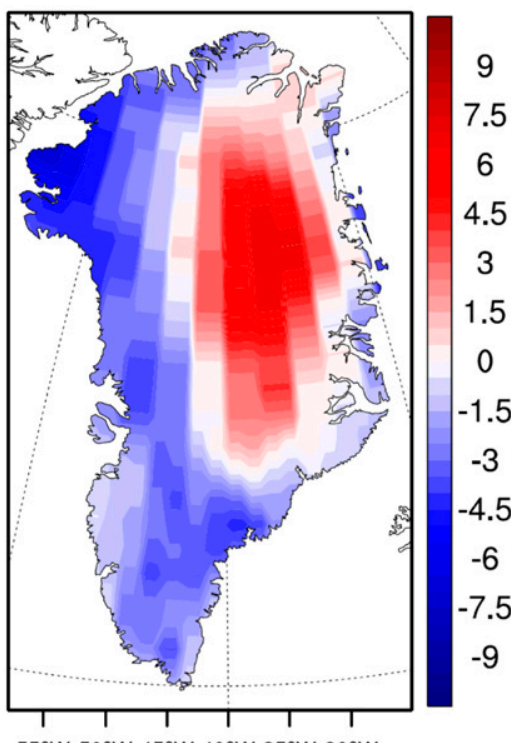

$55^{\circ} \mathrm{W} 50^{\circ} \mathrm{W} 45^{\circ} \mathrm{W} 40^{\circ} \mathrm{W} 35^{\circ} \mathrm{W} 30^{\circ} \mathrm{W}$

FIG. 3. Total cloud cover (\%) anomalies during high decile GBI summers compared to the common 2000-15 period for (a) ERAInterim reanalysis, (b) the MAR regional climate model, and (c) CERES EBAF, which uses MODIS Terra data for March 2000 through June 2002 and MODIS Terra and Aqua for July 2002 onward. Stippling indicates anomalies significant at the $95 \%$ confidence level for high GBI summers compared to $2000-15$ conditions.

the importance of enhanced moisture transport for heightened Greenland melt, potentially through the water vapor greenhouse effect, latent heat release due to condensation and due to rain freezing on the ice sheet, and formation of clouds with longwave radiative warming effects (Bennartz et al. 2013; Bonne et al. 2015; Doyle et al. 2015; Mattingly et al. 2016, 2018; Miller et al. 2015; Neff et al. 2014; Van Tricht et al. 2016). Increased moisture transport during high pressure years may also boost orographic lift effects, as forced ascent would be more effective with moister air for increasing cloud cover.

In addition to illustrating potential reasons for heightened orographic effects during high pressure summers, comparison of high and low pressure summers highlights the influence of temperature on cloud cover anomalies. During low pressure summers, reduced specific humidity alone (Fig. 5e) would promote reduced cloud cover over the entire ice sheet. Instead, anomalous cooling (Fig. 5f) promotes lower saturation vapor pressures and therefore increased relative humidity and cloud cover (Figs. 5b,d). However, regions of less negative specific humidity anomalies map onto the strongest cloud cover gains in northern, central, and southern Greenland.

During high pressure summers, warmer temperatures (Fig. $5 \mathrm{~m}$ ) promote reduced relative humidity (Fig. 5k) and cloud cover (Fig. 5i) everywhere except northeastern Greenland, where enhanced moisture and weaker warming combine to increase cloud cover. These results demonstrate that in addition to the contributions of moisture intrusions, temperature anomalies are necessary to explain the sign of the relative humidity and cloud cover response to high pressure conditions. An additional impact of warmer temperatures over western Greenland during high pressure summers may be enhanced temperature and therefore pressure gradients between the ice sheet and tundra, strengthening downslope katabatic winds and cloud dissipation.

\section{Radiative impacts of cloud cover changes}

\section{a. All-sky surface energy balance}

We are ultimately interested in the impact of Greenland blocking and resulting cloud cover changes on the surface energy balance, which controls surface melt. Figure 6 shows anomalies in surface energy components from MAR during high pressure summers with the exception of the ground heat flux term, which is very small (Box et al. 2012; Franco et al. 2013). Longwave downwelling radiation (LWD) increases over most of the GrIS, with the strongest anomalies over northern Greenland, while shortwave downwelling radiation (SWD) decreases slightly in northern, central Greenland and increases strongly to the south. Reduced albedo in the ablation zone promotes absorption of SWD and significant anomalies in shortwave net radiation (SWnet) 
a) $R^{2}$ all years

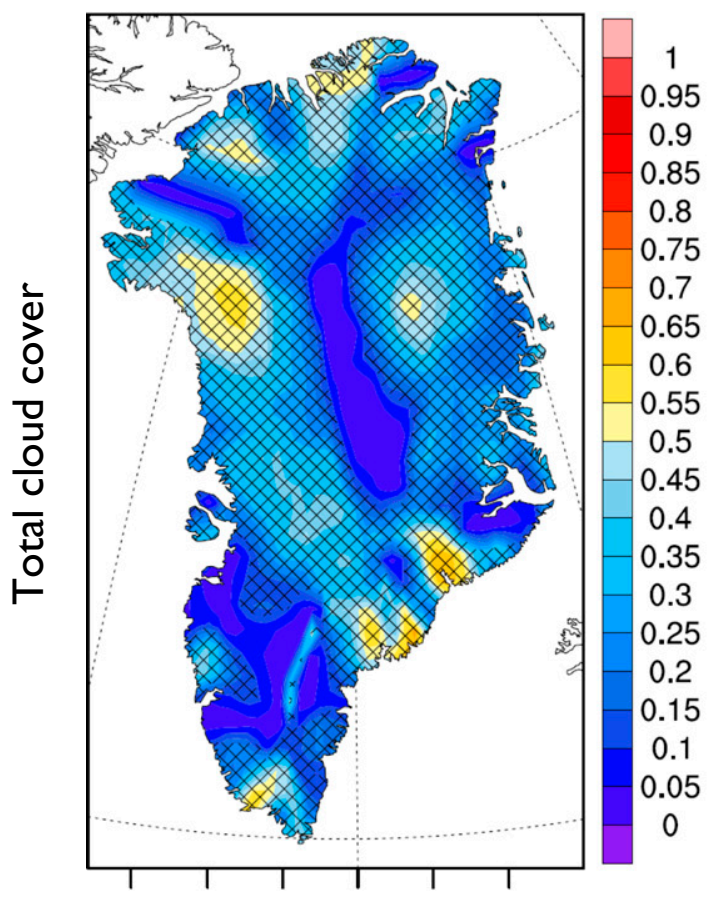

$55^{\circ} \mathrm{W} 50^{\circ} \mathrm{W} 45^{\circ} \mathrm{W} 40^{\circ} \mathrm{W} 35^{\circ} \mathrm{W} 30^{\circ} \mathrm{W}$

c) $R^{2}$ all years

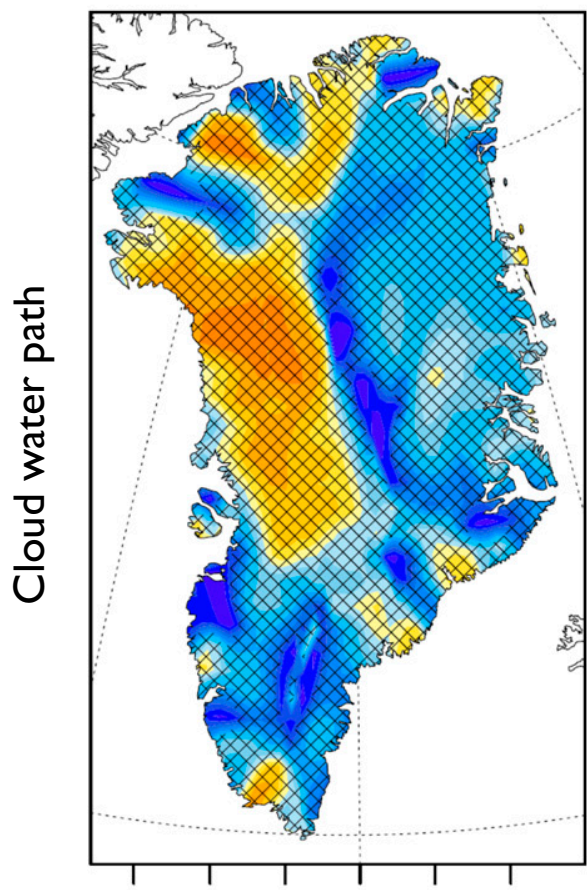

$55^{\circ} \mathrm{W} 50^{\circ} \mathrm{W} 45^{\circ} \mathrm{W} 40^{\circ} \mathrm{W} 35^{\circ} \mathrm{W} 30^{\circ} \mathrm{W}$

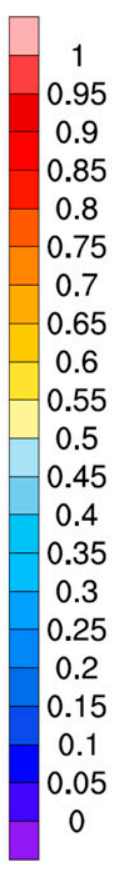

b) $R^{2}$ high pressure years

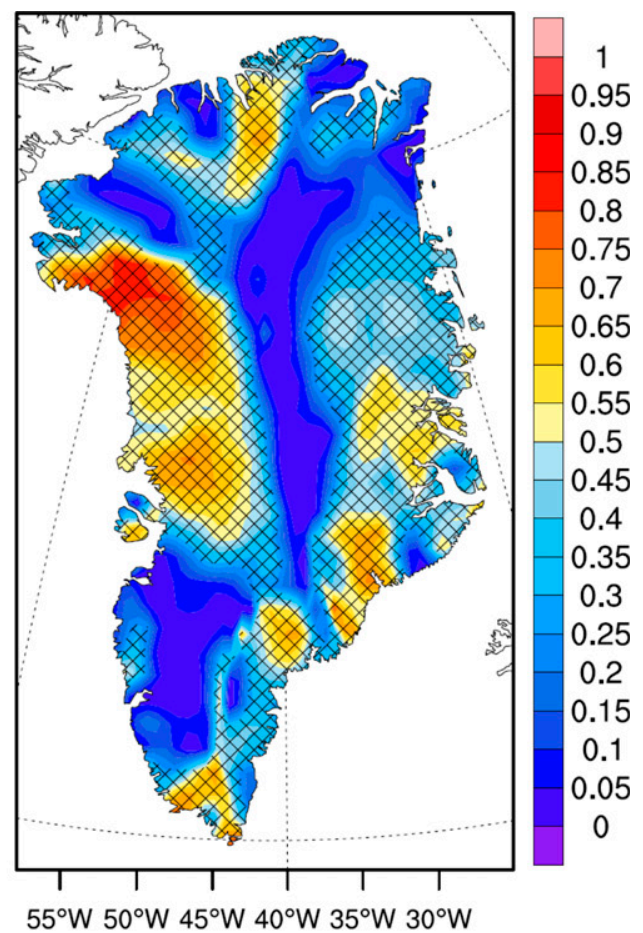

d) $R^{2}$ high pressure years

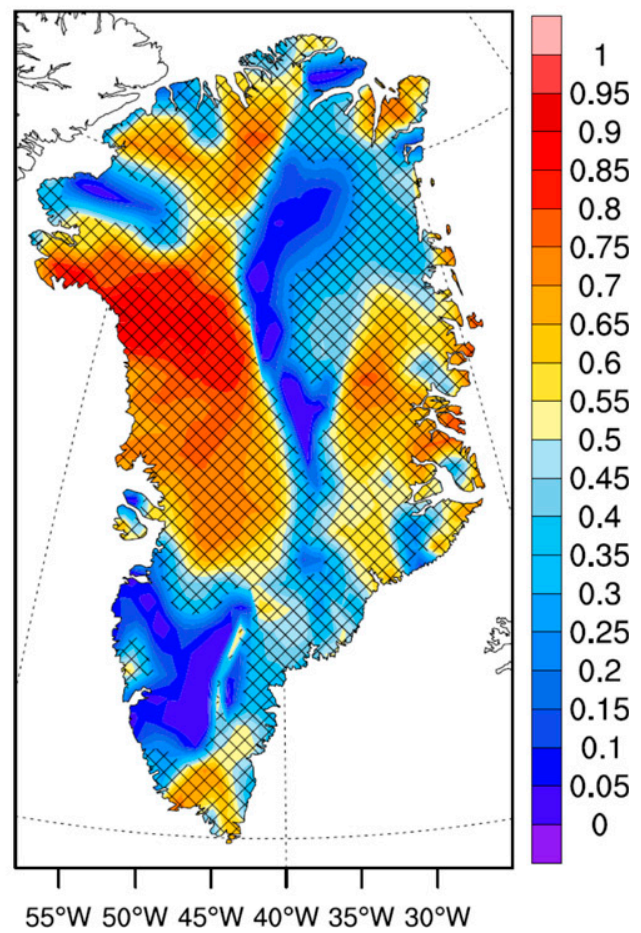

FIG. 4. $R^{2}$ value for regression of ERA-Interim JJA cross-barrier wind with (a),(b) total cloud cover and (c),(d) total cloud water path for (left) all years and (right) high pressure years only, with shading for significance at the 95\% confidence level. High pressure years are defined here as years with GBI values above the 1979-2015 average. 
a) Z500, UV500

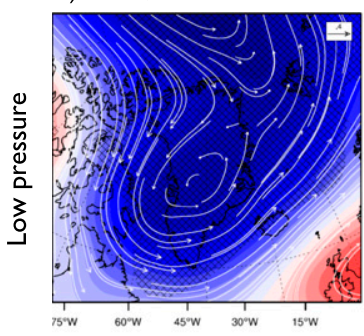

h) Z500, UV500

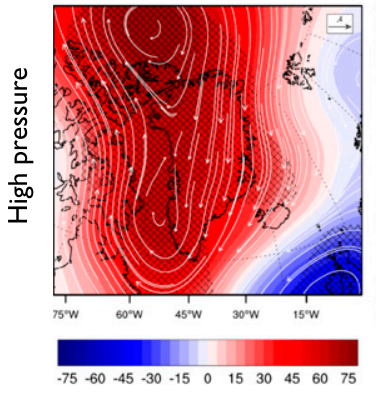

b) Cloud cover

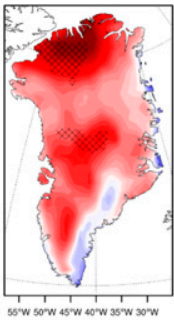

i) Cloud cover

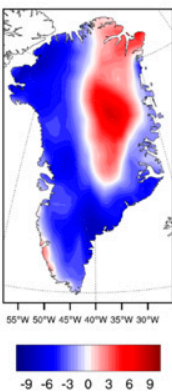

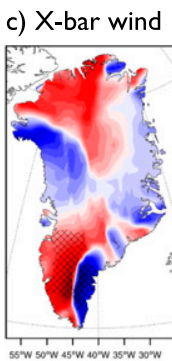

j) X-bar wind

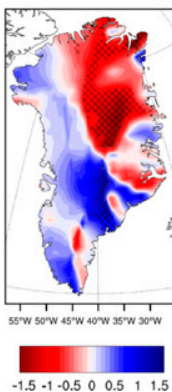

d) $\mathrm{RH} 200-1000$

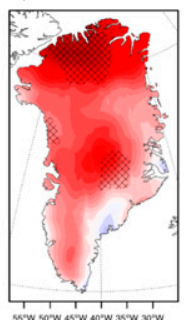

$\begin{array}{lll}\text { k) } \mathrm{RH} 200-1000 & \text { I) } \mathrm{Q} 200-1000\end{array}$

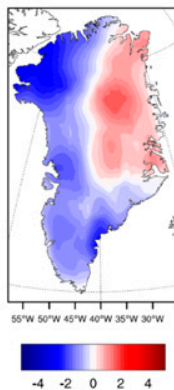

e) Q200- 1000
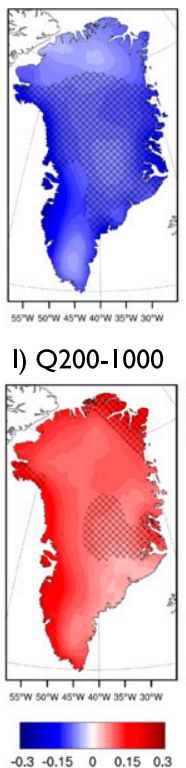

f) $T 200-1000$

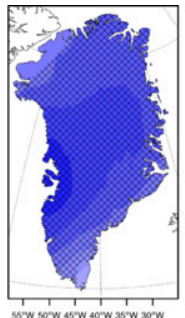

m) T200- 1000

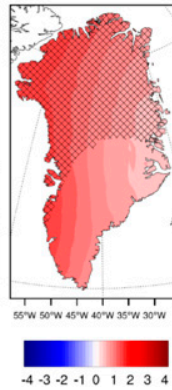

g) Frontal frequency

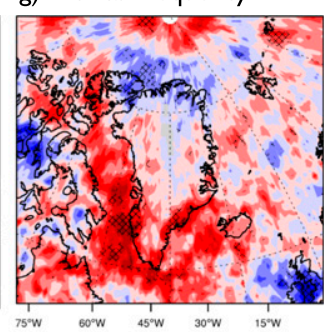

n) Frontal frequency

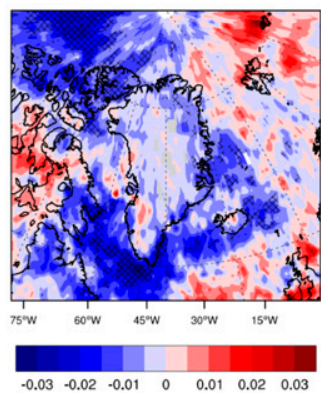

FIG. 5. ERA-Interim JJA anomalies for summers with pressure in the (top) lowest and (bottom) highest decile compared to all summers for the full 1979-2015 period for (a),(h) Z500 (contours; $\mathrm{m}$ ) and UV500 (vectors; $\mathrm{m} \mathrm{s}^{-1}$ ); (b),(i) cloud cover (\%); (c),(j) cross-barrier wind $\left(X\right.$-bar wind; $\left.\mathrm{m} \mathrm{s}^{-1}\right) ;(\mathrm{d}),(\mathrm{k})$ relative humidity $(\mathrm{RH} 200-1000 ; \%) ;(\mathrm{e}),(\mathrm{l})$ specific humidity (Q200-1000; $\left.\mathrm{g} \mathrm{kg}^{-1}\right)$; and (f),(m) temperature (T200-1000; ${ }^{\circ} \mathrm{C}$ ) all vertically averaged from 200 to $1000 \mathrm{mb}$, weighted by pressure level thickness; as well as (g),(n) frontal frequency. Stippling indicates anomalies significant at the 95\% confidence level compared to 1979-2015 conditions.

in southern and marginal Greenland, while high albedo in the accumulation region dampens SWnet effects for central Greenland. In response to high pressure conditions, reduced cloud cover over the southern and peripheral GrIS promotes predominantly shortwave (SW) warming in the ablation zone, while increased cloud cover in central, northern Greenland promotes predominantly longwave (LW) warming effects in the accumulation zone, both of which favor extreme melt. These results highlight the important role of albedo in setting the radiative response to blocking-induced cloud changes over Greenland, consistent with Wang et al. (2018).

In addition to surface albedo, cloud properties such as cloud altitude and liquid water content can impact the relative influence of Greenland cloud SW cooling versus LW warming effects. For example, low-level, liquidcontaining clouds have been shown to contribute stronger LW surface warming than SW surface cooling in the accumulation zone (Bennartz et al. 2013; Miller et al. 2015; Wang et al. 2018, 2019). Our results are consistent with previous literature demonstrating a SW warming response to reduced Greenland cloud cover, particularly in ablation regions and for the area-averaged ice sheet (Box et al. 2012; Hofer et al. 2017; Lim et al. 2016; Wang et al. 2018, 2019), as well as with studies finding LW warming effects of enhanced cloud cover over accumulation regions (Bennartz et al. 2013; Miller et al. 2015; Wang et al. 2018, 2019).
We additionally plot sensible and latent heat fluxes, as well as LWnet and total net radiation. Consistent with Van den Broeke et al. (2011), sensible and latent heat flux anomalies (Figs. 6e,f) during high pressure summers are smaller than the radiative fluxes, although sensible warming aligns with the pattern of anomalous melt and is especially prominent near the tundra. Anomalous longwave upward radiation over the warmer ice sheet promotes a LWnet cooling effect, with the exception of northeastern Greenland. Here, LWD anomalies dominate LWU anomalies to promote a warming impact for LWnet and total net radiation.

Using the common $2000-15$ base period, Fig. 7 compares LWD, SWD, and SWnet anomalies in MAR with CERES EBAF, which will be used to estimate the CRE. Anomalies in both SWD and LWD surface radiation in northern Greenland are stronger for CERES EBAF than for MAR. However, both datasets show a similar pattern of LWD warming, especially in northern Greenland, with SWD cooling in northern Greenland and warming in southern Greenland. Both datasets highlight the role of albedo in producing dominant SWnet warming in southern and peripheral Greenland, where SWD warming is amplified, and dominant LWD warming in northern, central Greenland, where SWD cooling is dampened. With satellite observations demonstrating results similar to MAR, we use CERES EBAF to further investigate CRE. 
a) LWD

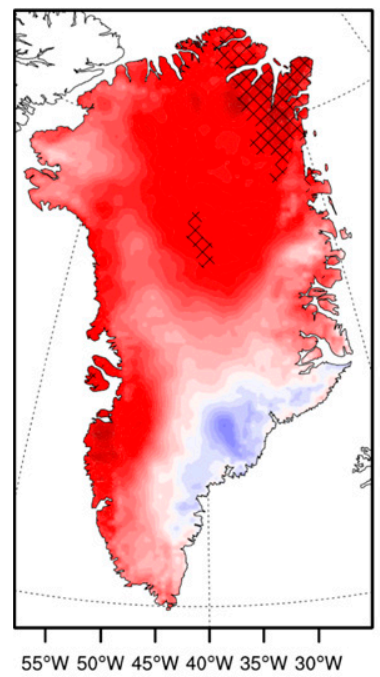

e) SHF

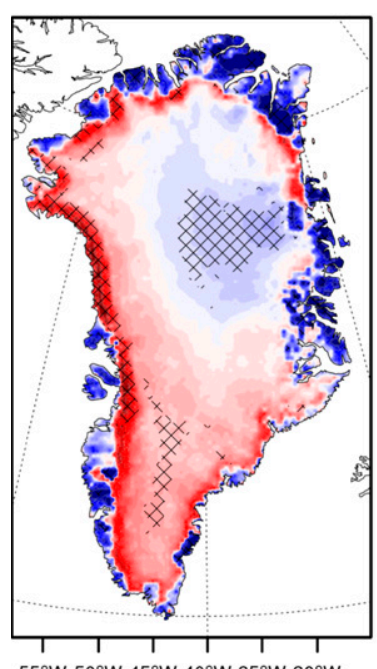

b) SWD

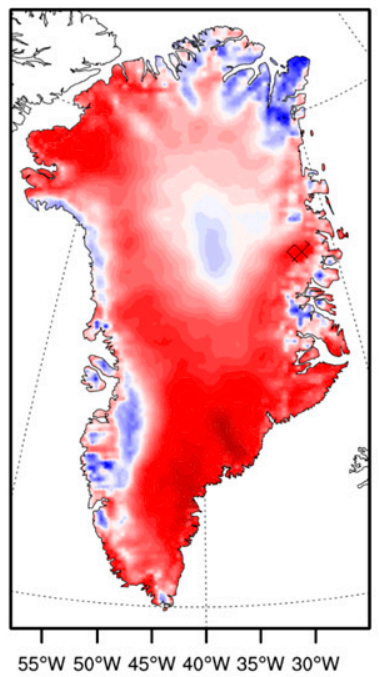

f) LHF

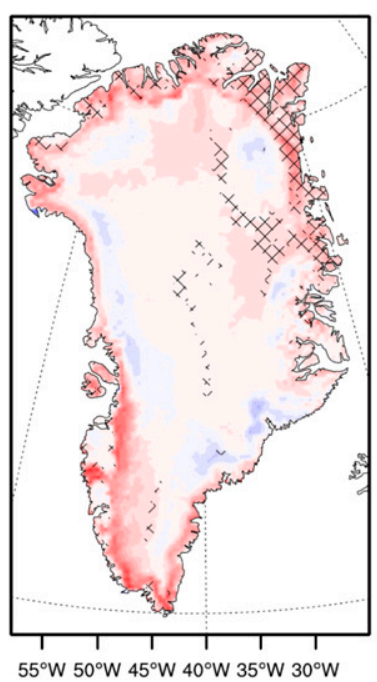

c) SWnet

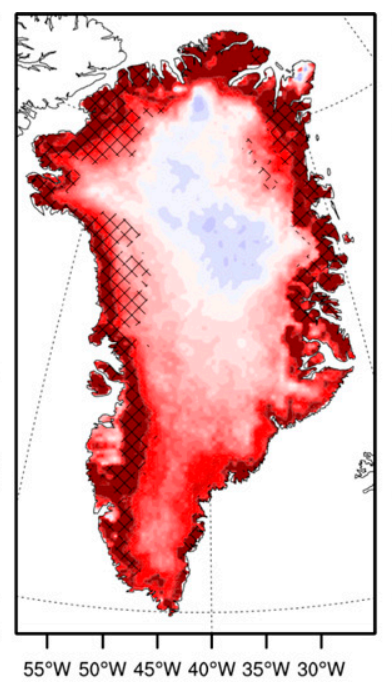

g) LWU

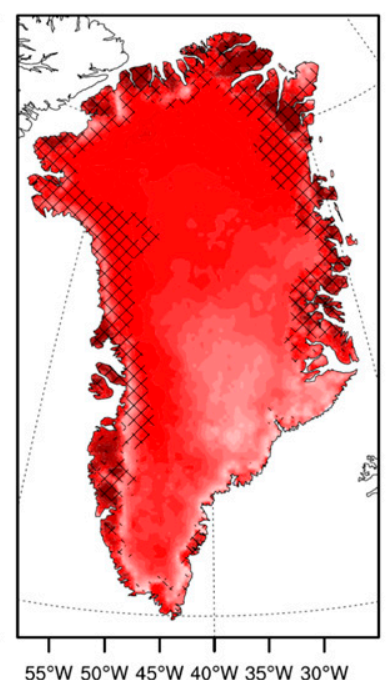

d) SWnet + LWnet

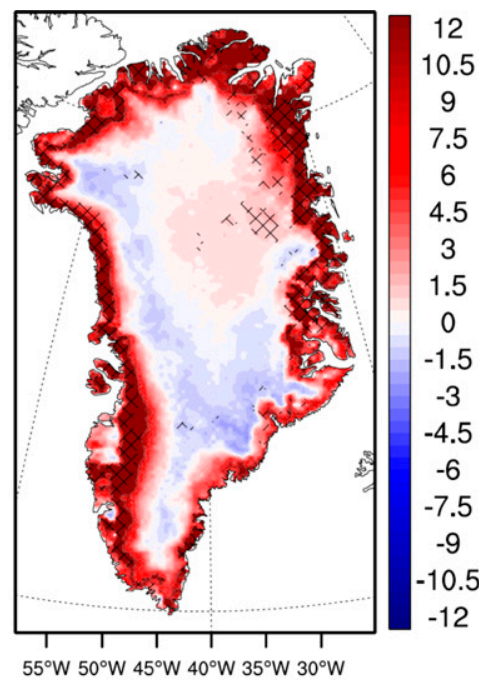

h) LWnet

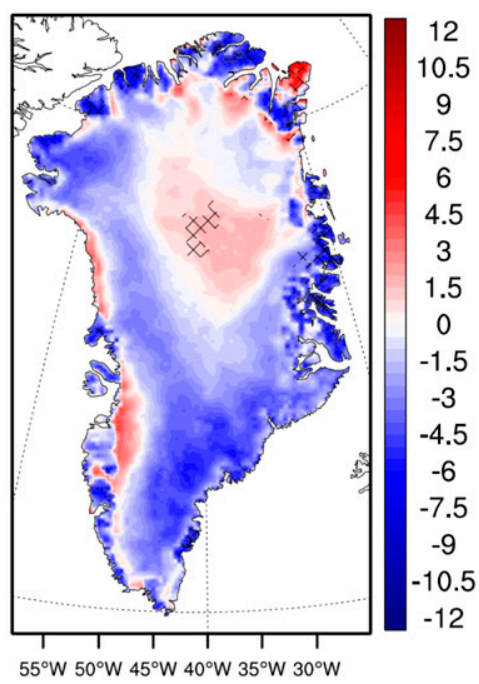

FIG. 6. JJA surface radiation anomalies from MAR for top decile GBI summers compared to 1979-2015 period for (a) longwave downwelling radiation (LWD; $\mathrm{W} \mathrm{m}^{-2}$ ), (b) shortwave downwelling radiation ( $\mathrm{SWD} ; \mathrm{W} \mathrm{m}^{-2}$ ), (c) shortwave net radiation, positive downward (SWnet; $\mathrm{W} \mathrm{m}^{-2}$ ), (d) total net radiation, positive downward (SWnet + LWnet; $\mathrm{W} \mathrm{m}^{-2}$ ), (e) sensible heat flux, positive downward (SHF; $\mathrm{W} \mathrm{m}^{-2}$ ), (f) latent heat flux, positive downward (LHF; $\mathrm{W} \mathrm{m}^{-2}$ ), (g) longwave upwelling radiation $\left(\mathrm{LWU}\right.$; $\left.\mathrm{W} \mathrm{m}^{-2}\right)$, and (h) longwave net radiation, positive downward $\left(\mathrm{LWnet} ; \mathrm{W} \mathrm{m}^{-2}\right.$ ). Stippling indicates anomalies significant at the $95 \%$ confidence level for high GBI summers compared to 1979-2015 conditions.

\section{b. CRE from CERES}

CERES EBAF provides all-sky and clear-sky surface radiative fluxes, from which all-sky minus clear-sky fluxes gives an estimate of the CRE, with anomalies shown for high pressure summers (Fig. 8). Comparison of the LWD CRE (Fig. 8b) with all-sky LWD anomalies (Fig. 7d) demonstrates that only northern central LW warming results from increased cloud cover, while reduced cloud cover over the rest of the ice sheet promotes LW cooling. Therefore, the all-sky LW warming over western and southern Greenland during extreme melt summers must be driven by clear-sky effects (Fig. 8a), such as enhanced water vapor and atmospheric warming. The surface receives slightly less all-sky SWD compared to the SWD CRE (Fig. 8c), consistent with clear-sky water vapor slightly attenuating incoming SW radiation.

\section{Flattened topography experiment}

\section{a. Elevation effects on temperature and moisture}

We further investigate orographic contributions to cloud cover and melt under high pressure conditions 
a) LWD

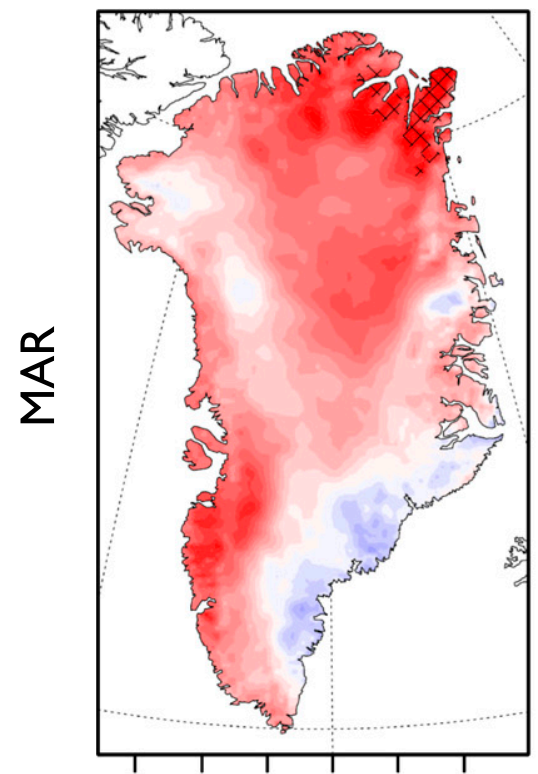

$55^{\circ} \mathrm{W} 50^{\circ} \mathrm{W} 45^{\circ} \mathrm{W} 40^{\circ} \mathrm{W} 35^{\circ} \mathrm{W} 30^{\circ} \mathrm{W}$

d) LWD

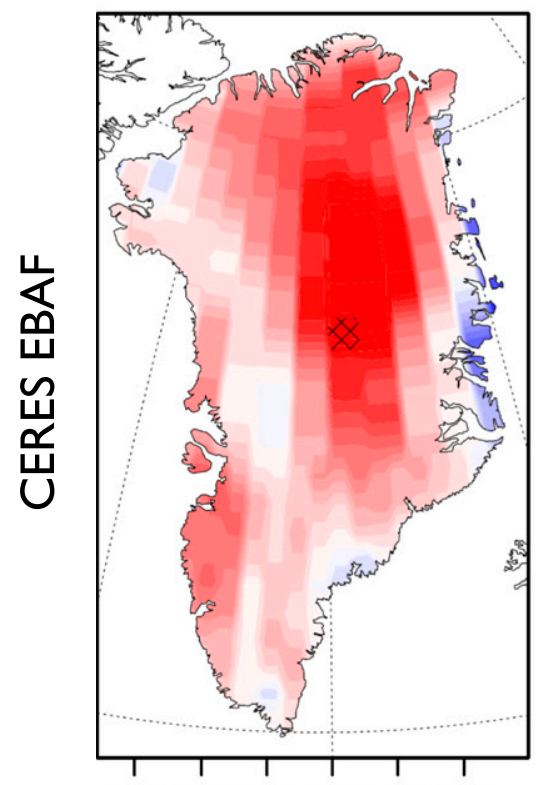

$55^{\circ} \mathrm{W} 50^{\circ} \mathrm{W} 45^{\circ} \mathrm{W} 40^{\circ} \mathrm{W} 35^{\circ} \mathrm{W} 30^{\circ} \mathrm{W}$ b) SWD

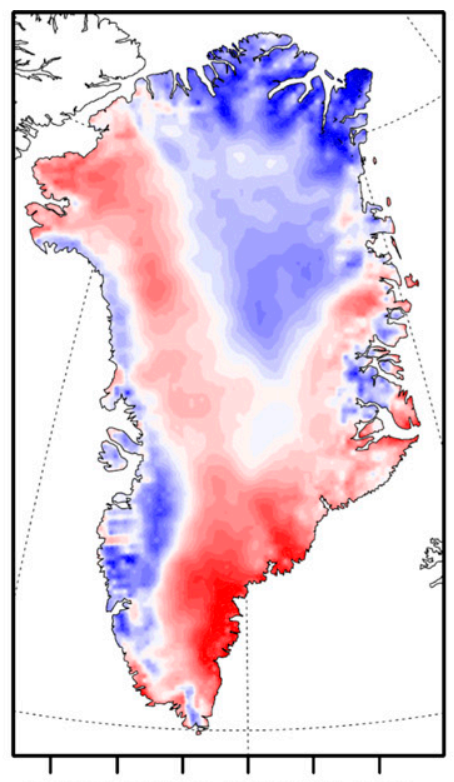

$55^{\circ} \mathrm{W} 50^{\circ} \mathrm{W} 45^{\circ} \mathrm{W} 40^{\circ} \mathrm{W} 35^{\circ} \mathrm{W} 30^{\circ} \mathrm{W}$

e) SWD

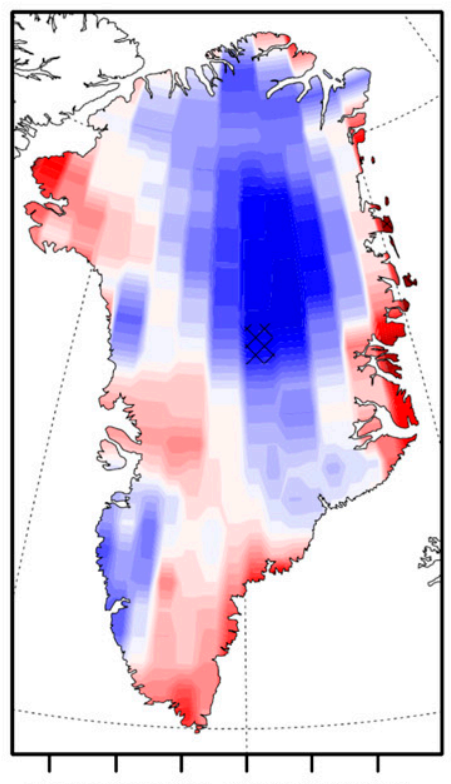

$55^{\circ} \mathrm{W} 50^{\circ} \mathrm{W} 45^{\circ} \mathrm{W} 40^{\circ} \mathrm{W} 35^{\circ} \mathrm{W} 30^{\circ} \mathrm{W}$

\section{c) SWnet}

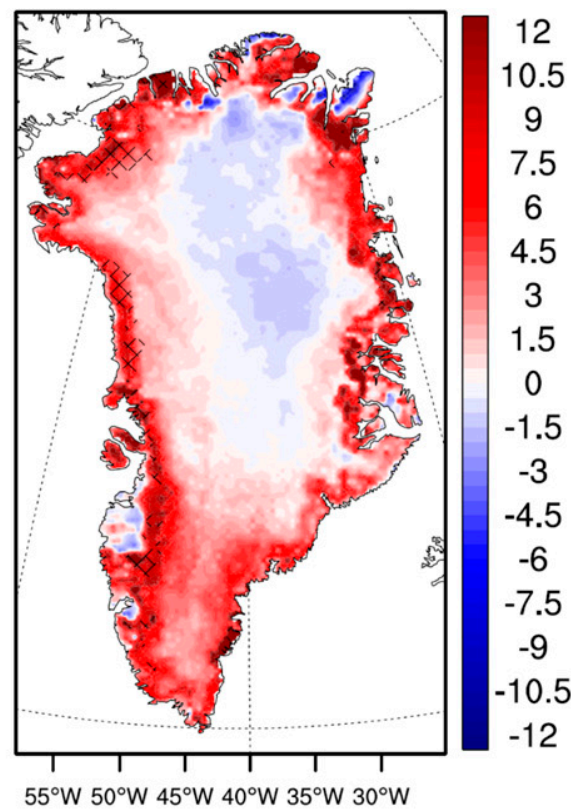

f) SWnet

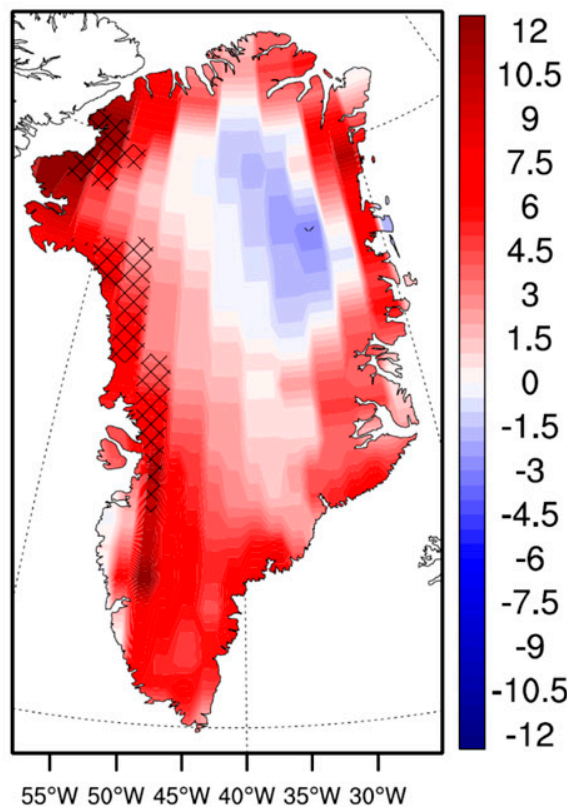

FIG. 7. Surface radiation anomalies for top decile GBI summers compared to 2000-15 period for (a),(d) longwave downwelling radiation (LWD; $\mathrm{W} \mathrm{m}^{-2}$ ), (b),(e) shortwave downwelling radiation ( $\mathrm{SWD} ; \mathrm{W} \mathrm{m}^{-2}$ ), and (c),(f) shortwave net radiation, positive downward (SWnet; $\mathrm{W} \mathrm{m}^{-2}$ ) for (top) MAR and (bottom) CERES EBAF. Stippling indicates anomalies significant at the $95 \%$ confidence level for high GBI summers compared to $2000-15$ conditions.

using a flattened topography experiment with the regional climate model MAR. Flattening the GrIS not only eliminates orographic lift and descent, but also introduces adiabatic warming and enhanced water vapor path. To estimate the effects of elevation on surface temperature in the control topography experiment, we calculate the midtropospheric lapse rate $\Gamma$ and surface elevation $z$ at each grid point. Removing the elevation 
a) LWD clear-sky

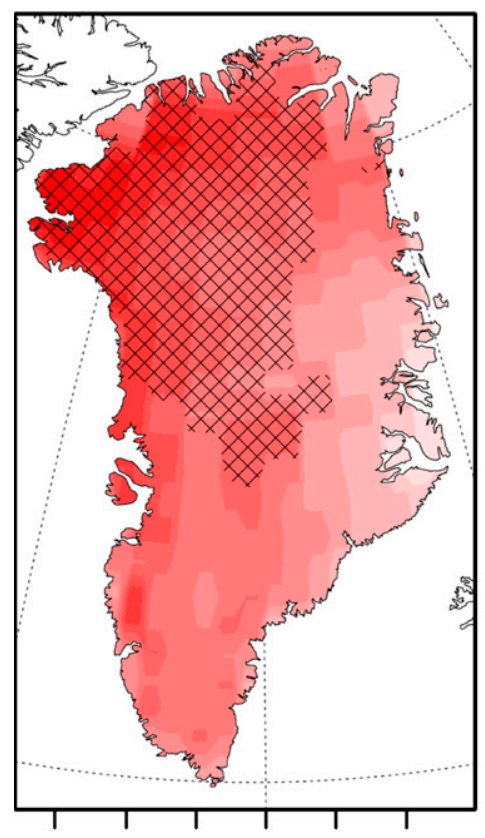

$55^{\circ} \mathrm{W} 50^{\circ} \mathrm{W} 45^{\circ} \mathrm{W} 40^{\circ} \mathrm{W} 35^{\circ} \mathrm{W} 30^{\circ} \mathrm{W}$ b) LWD CRE

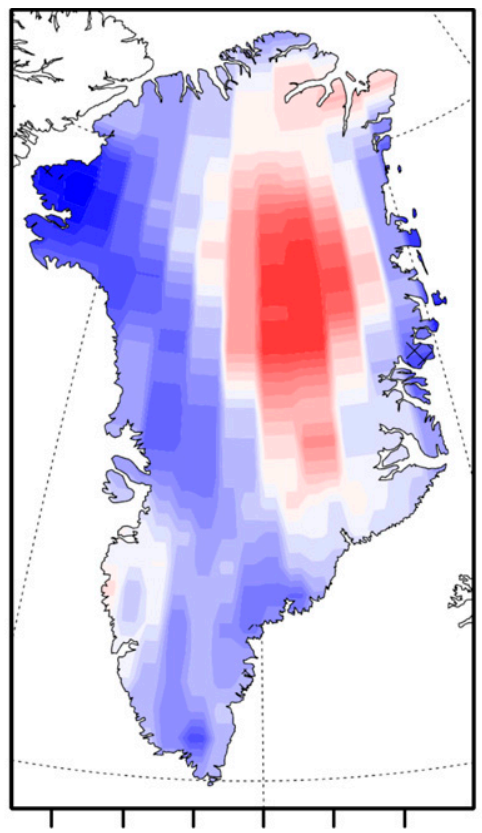

$55^{\circ} \mathrm{W} 50^{\circ} \mathrm{W} 45^{\circ} \mathrm{W} 40^{\circ} \mathrm{W} 35^{\circ} \mathrm{W} 30^{\circ} \mathrm{W}$ c) SWD CRE

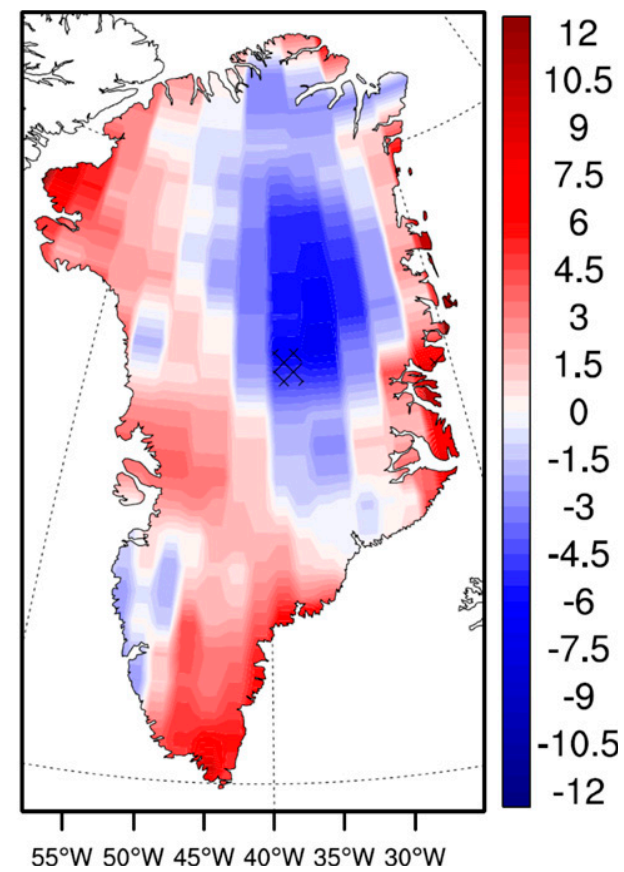

FIG. 8. Surface radiation anomalies during top decile GBI summers compared to 2000-15 period for (a) clear-sky longwave downwelling radiation (LWD; $\mathrm{W} \mathrm{m}^{-2}$ ) and for all-sky minus clear-sky (b) longwave downwelling radiation (LWD; W m ${ }^{-2}$ ) and (c) shortwave downwelling radiation (SWD; $\mathrm{W} \mathrm{m}^{-2}$ ) from CERES-EBAF. Stippling indicates anomalies significant at the $95 \%$ confidence level for high GBI summers compared to $2000-15$ conditions.

effect $(-\Gamma \times z)$ from the surface temperature gives elevation-corrected surface temperature in the control experiment, which is then area-averaged over the GrIS in Fig. 9a.

This elevation effect strongly promotes warmer surface temperatures for the flat experiment compared to the control, as the flat experiment is colder than the elevationcorrected control experiment. Lapse rate warming also promotes higher GrIS area-averaged water vapor path in the flat experiment (Fig. 9b), which may be further enhanced due to the removal of a physical barrier to water vapor intrusions over Greenland. These elevation-driven temperature and water vapor differences combine with different orographic lift and descent to produce distinct cloud and melt responses in the flat and control experiments.

\section{b. Cloud cover and surface energy trends}

As the control and flat topography experiments are forced identically with ERA-Interim fields at the lateral boundaries of the MAR domain, geopotential heights are similar for both experiments, as diagnosed using the summer GBI (Fig. 10a). The GBI is calculated over the standard latitude range but over a reduced longitude range, corresponding to the limits of the MAR domain (which are shown in Fig. 12a). While GBI values are slightly larger for the control than for the flat topography experiment, both show similar interannual variability and trend toward stronger Greenland blocking beginning in the mid-1990s.

Although both experiments undergo a similar increase in blocking beginning in the mid-1990s, only the control experiment displays a significant downward trend in GrIS area-averaged cloud cover anomalies from 1994 to 2017, with cloud cover percent decreasing $6.4 \%\left(R^{2}=0.42\right.$, $P<0.001$; Figs. 10b,d). This reduction is comparable with the $-6.1 \%$ change in MAR cloud cover observed from 1994 to 2015 by Hofer et al. (2017).

For the 1994-2017 period in the flat topography experiment, cloud cover instead increases over Greenland, highlighting a key role for Greenland topography in shaping the cloud cover response to blocking. Orographic descent combined with the ice sheet's physical barrier to water vapor intrusions were essential to produce the observed negative cloud cover trend in response to stronger blocking since the mid-1990s. Due to the exponential dependence of atmospheric moisture on temperature, the same rise in temperature in the initially warmer, flat 


\section{a) Surface temperature $\left({ }^{\circ} \mathrm{C}\right)$}

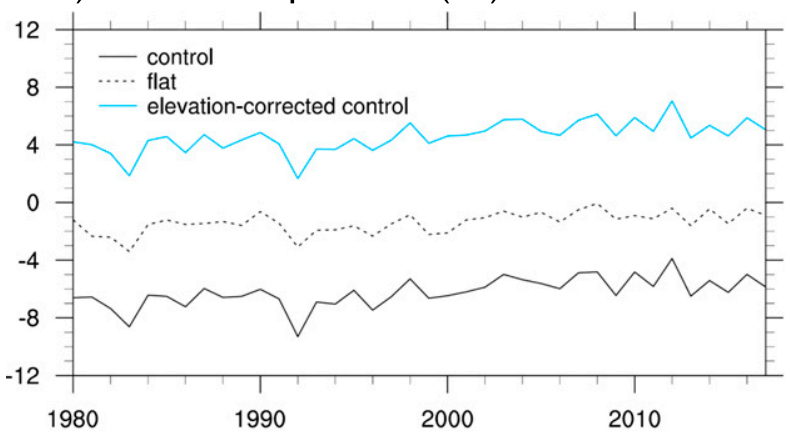

b) Water vapor path $\left(\mathrm{kg} / \mathrm{m}^{2}\right)$

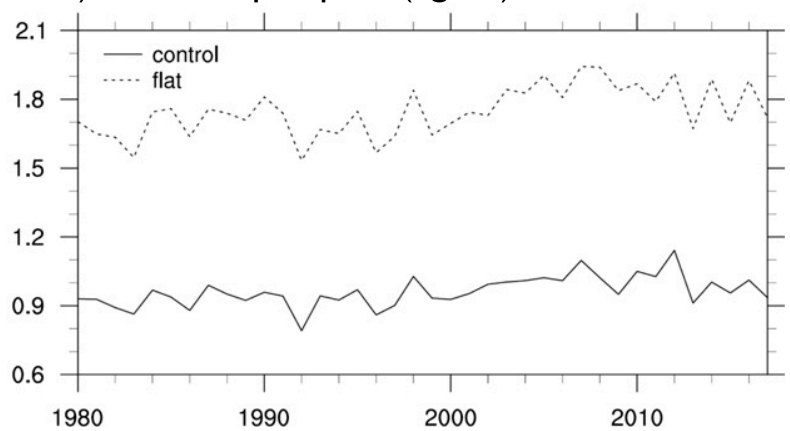

FIG. 9. JJA means for flat (dashed) and control (solid) MAR topography experiments from 1980-2017 for (a) surface temperature $\left({ }^{\circ} \mathrm{C}\right)$ and (b) water vapor path $\left(\mathrm{kg} \mathrm{m}^{-2}\right)$, both area-averaged over Greenland. For (a), the elevation-corrected control (blue; ${ }^{\circ} \mathrm{C}$ ) shows surface temperature in the control experiment with the lapse rate elevation effect $(-\Gamma \times z)$ removed.

experiment contributes to stronger increased water vapor than in the initially colder, control experiment, which may also promote cloud cover differences between experiments under increased blocking.

Declining cloud cover since the mid-1990s allowed more shortwave radiation to reach the ice sheet surface (Hofer et al. 2017), promoting a surface SWD increase of $7.3 \mathrm{~W} \mathrm{~m}^{-2}$ from 1994 to 2017 for the control experiment $\left(R^{2}=0.29, P=0.007\right.$; Figs. $\left.10 \mathrm{c}, \mathrm{e}\right)$, in contrast with reduced SWD in the flat experiment. SWD enhancement for the control run is strongest and most significant for southern Greenland (Fig. 10e), corresponding to the strongest cloud cover reductions (Fig. 10d). In addition to the impact of orographically driven cloud cover differences on SWD, topographic differences may affect SWD by changing the zenith angle of incoming sunlight. For example, flattening originally south-facing slopes may reduce the surface SWD radiation and alter the SW CRE (Shupe and Intrieri 2004). However, as we are considering anomalies within each simulation, and as zenith angle effects apply to the entire time period, we do not expect zenith angle differences to account for the control experiment's stronger rise in shortwave radiation for 1994-2017. Trends for anomalies in other surface energy components do not differ significantly between the flat and control experiments.

\section{c. Extreme 2012 melt}

Due to lapse rate effects and greenhouse warming from excess water vapor, the flat topography experiment undergoes more melt than the control experiment for the full 1980-2017 period (Fig. 11a). Both the flat and control experiments shift toward stronger melt beginning in the mid-1990s, indicating that increased blocking drives increased Greenland melt in the absence of topography. This warming trend in the flat experiment may result in part from longwave warming due to increased water vapor. An additional factor promoting warming over Greenland in both experiments is enhanced warm-air advection from the south under high pressure conditions.

However, only the control topography experiment exhibits extreme melt for summer 2012 in comparison with other summers, while summer 2012 melt in the flat topography experiment is comparable with summer melt in the surrounding decade. Calculating summer melt as a fraction of the 1980-2017 mean within each simulation (Fig. 11b) demonstrates almost twice the long-term mean melt in summer 2012 for the control run, while 2012 melt in the flat experiment is on par with other recent summers. These results highlight an additional role for topographic effects in producing the extreme melt observed in summer 2012.

We investigate conditions producing extreme 2012 melt for the control experiment by comparing summer 2012 anomalies with the 1980-2017 period within each experiment, as well as the difference between anomalies in these experiments (Fig. 12). Due to identical boundary forcing, both experiments show similar geopotential height anomalies, although these heights are centered to the west of the ice sheet in the control and directly over the ice sheet in the flat experiment (Fig. 12a). Differences in circulation anomalies do not explain the more extreme 2012 melt in the control experiment, as the control experiment actually displays slightly weaker anticyclonic circulation anomalies than the flat experiment.

Increased water vapor is limited to the western and northern ice sheet in the control experiment, as Greenland topography both blocks water vapor (directly and through wind effects) and squeezes it out of ascending, northerly flow before it descends over the southern ice sheet (Fig. 12b). In the flat experiment, water vapor anomalies extend farther into central Greenland, while remaining strongest on the western coast. 


\section{a) Greenland Blocking Index (m)}

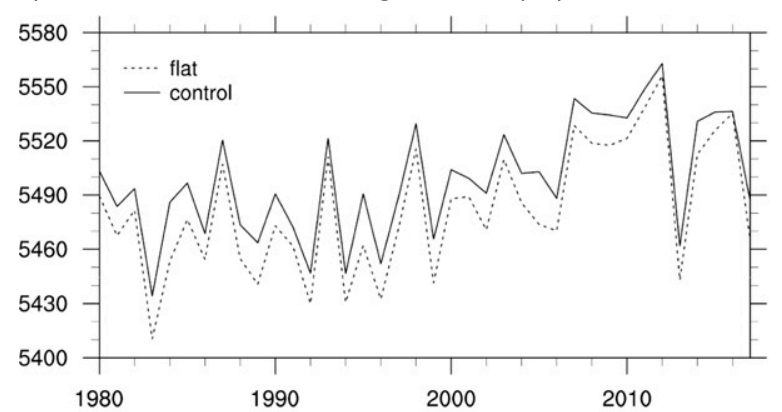

b) Cloud cover anomalies (\%)

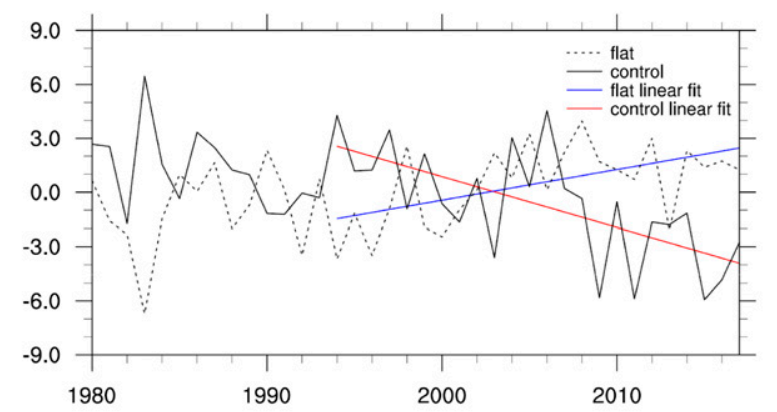

c) SWD anomalies $\left(\mathrm{W} / \mathrm{m}^{2}\right)$

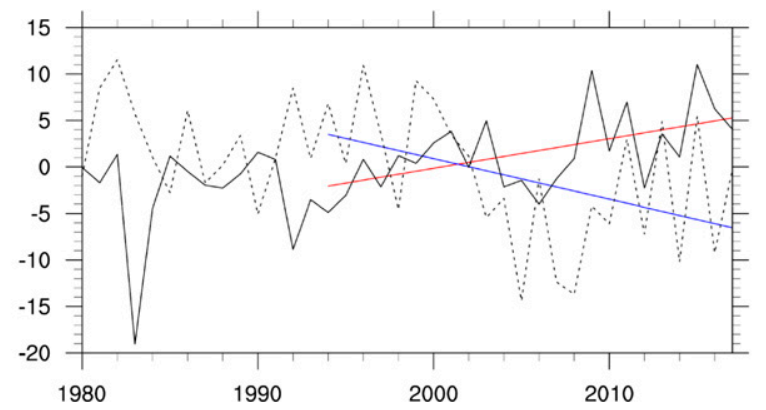

d) 1994-2017 Cloud Cover Change (\%)
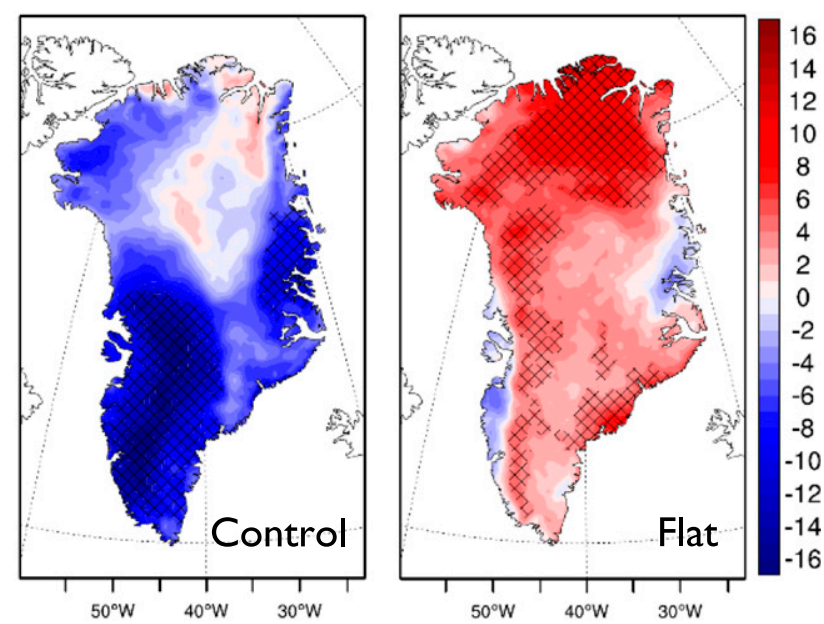

e) 1994-2017 SWD Change $\left(\mathrm{W} / \mathrm{m}^{2}\right)$

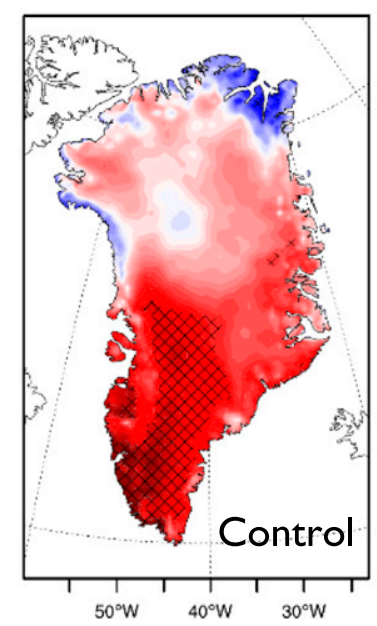

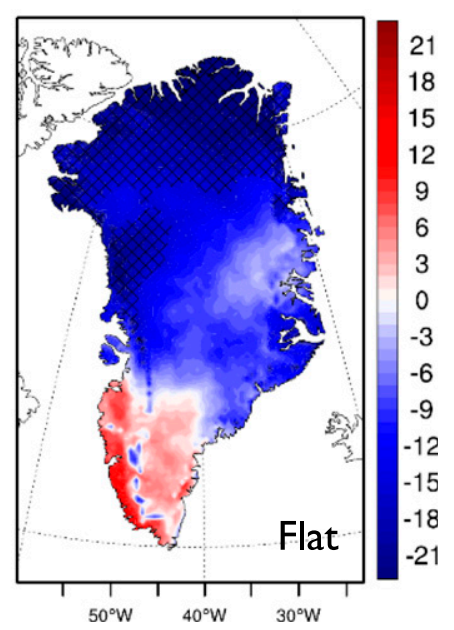

FIG. 10. (a) JJA Greenland blocking index (GBI; m), (b) JJA cloud cover anomalies over Greenland (\%), and (c) JJA surface shortwave downwelling radiation anomalies over Greenland $\left(\mathrm{SWD} ; \mathrm{W} \mathrm{m}^{-2}\right.$ ) for flat (dashed) and control (solid) MAR topography experiments from 1980 to 2017. Linear fit for 1994-2017 control cloud cover anomalies (red; $R^{2}=0.42, P<0.001$ ) and flat cloud cover anomalies (blue; $\left.R^{2}=0.31, P=0.004\right)$ and for control SWD anomalies (red; $\left.R^{2}=0.29, P=0.007\right)$ and flat SWD anomalies $\left(\right.$ blue; $\left.R^{2}=0.18, P=0.04\right)$. (d) Cloud cover and (e) SWD JJA trends for 1994-2017 from linear regression analysis, with shading for significance at the 95\% confidence level.

In the control experiment, increased upslope flow in northern Greenland produces increased cloud cover, while downslope flow reduces cloud cover particularly in the southeast (Fig. 12c). While cloud cover also increases in northern Greenland in the flat experiment, likely due to enhanced water vapor, cloud cover reductions over southern Greenland are much stronger for the control experiment than the flat experiment. This demonstrates a role for orographic descent in reducing southern Greenland cloud cover in summer 2012.

Longwave warming in 2012 is similar between the flat and control experiments, although the control experiment shows stronger LWD in southwest Greenland, potentially due to larger liquid water path (Figs. 12d and 13a). Stronger cloud cover reductions produce stronger SWD warming in the control experiment over southern Greenland (Fig. 12e). Additionally, weaker increased cloud cover in northern Greenland due to weaker water vapor anomalies in the control run weakens SW cooling over this region in comparison with the flat topography experiment.

SWnet radiation anomalies (Fig. 12f) ultimately contribute most to extreme melt in summer 2012 (Fig. 12g), with darker surfaces amplifying SW warming in southern 


\section{a) Melt (mmWE/day)}

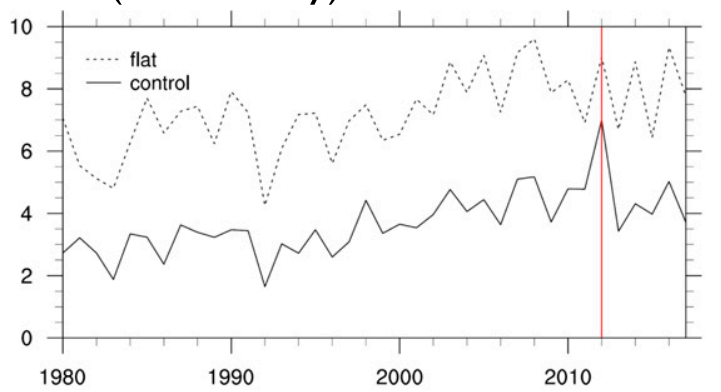

b) Melt as a fraction of long-term mean melt

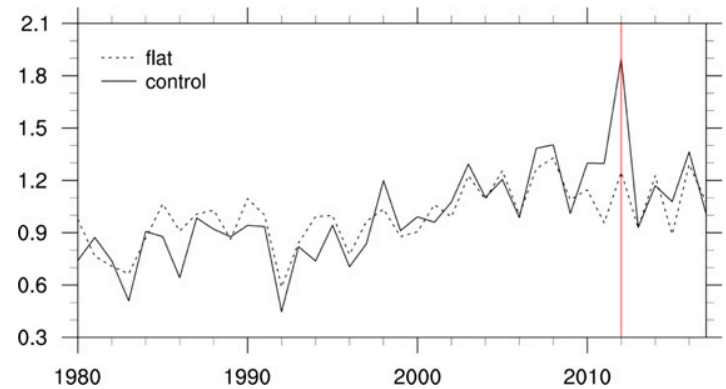

FIG. 11. (a) JJA melt $\left(\mathrm{mmWEday}^{-1}\right)$ area averaged over Greenland for flat (dashed) and control (solid) MAR topography experiments from 1980 to 2017, and (b) JJA Greenland melt as a fraction of the 1980-2017 mean summer melt for each MAR topography experiment, with red vertical line for 2012.

and peripheral Greenland and brighter surfaces dampening SW cooling anomalies in northern central Greenland. While turbulent flux anomalies are much smaller than radiative flux anomalies, albedo differences between experiments are collocated with SHF differences (Figs. 13c,d). Stronger downward SHF over southern and peripheral Greenland may support lower albedo and enhanced SWnet in the control experiment than the flat experiment, contributing to the pattern of SWnet and melt anomalies.

\section{Summary and conclusions}

We use reanalysis data, satellite observations, and a regional climate model to investigate the impact of high pressure systems on Greenland clouds and melt. Composite anomaly and regression analyses show that anticyclonic circulation anomalies interact with Greenland topography to produce orographic lift and descent, which correlate with the cloud cover response to blocking. Orographic effects are particularly linked to cloud cover during high blocking summers, potentially due to reduced frontal activity. While blocking-induced moisture intrusions contribute to the pattern of cloud cover changes, temperature anomalies control the sign of these changes: stronger warming in southern and western Greenland increases saturation vapor pressure and reduces cloud cover in these regions, while weaker warming in central, northern Greenland allows for increased cloud cover as specific humidity increases.

Previous studies have highlighted either the shortwave cooling (Box et al. 2012; Lim et al. 2016; Hofer et al. 2017) or longwave warming (Bennartz et al. 2013; Miller et al. 2015; Van Tricht et al. 2016) impact of Greenland cloud changes. In consideration of the entire GrIS, Wang et al. $(2018,2019)$ find dominant SW (LW) CRE over low (high) albedo surfaces. Consistent with these studies, we find that increased cloud cover under blocking conditions drives dominant LW warming over high albedo, high elevation regions of the GrIS. In contrast, reduced cloud cover drives dominant SW warming over low albedo, low elevation regions under blocking conditions. Additional clear sky LW warming counteracts cloud-driven LW cooling over southern and peripheral Greenland to produce all-sky LW warming over the entire ice sheet.

SW warming in the ablation zone currently dominates the melt signal, as warm mean-state temperatures allow energy anomalies to produce melting, while LW warming in the colder accumulation zone largely contributes to snowpack heating. As temperatures rise in the current accumulation zone, blocking-induced LW warming may become more important for Greenland melt, although reduced albedo will also intensify SW effects in this region. With warming, melt-induced surface albedo reduction will increase susceptibility to cloud cover changes via shortwave radiative effects.

Last, a flattened topography experiment using MAR indicates that orographic effects were required to produce GrIS-averaged declining cloud cover and increased SWD observed since the mid-1990s. Increased melt since the mid-1990s is observed in both the flat and control topography experiments, potentially due to enhanced warm air advection under high pressure conditions in both experiments. However, these experiments suggest an additional role for topography in promoting melt, as only the control topography experiment demonstrates the extreme melt observed in 2012.

These results suggest that future melt will depend on the pattern of circulation anomalies as well as the shape of the GrIS. We expect blocking patterns that produce stronger northerly downslope winds over southern Greenland to contribute to stronger cloud cover reductions and SW surface warming.

Additionally, changes in Greenland topography due to global warming-induced melt may impact the influence of high pressure conditions on Greenland melt in a potentially positive feedback. Projections of ice sheet 
a) UV, Z500

b) WVP

c) $\mathrm{CC}$

d) LWD

e) SWD

f) SWnet

g) Melt
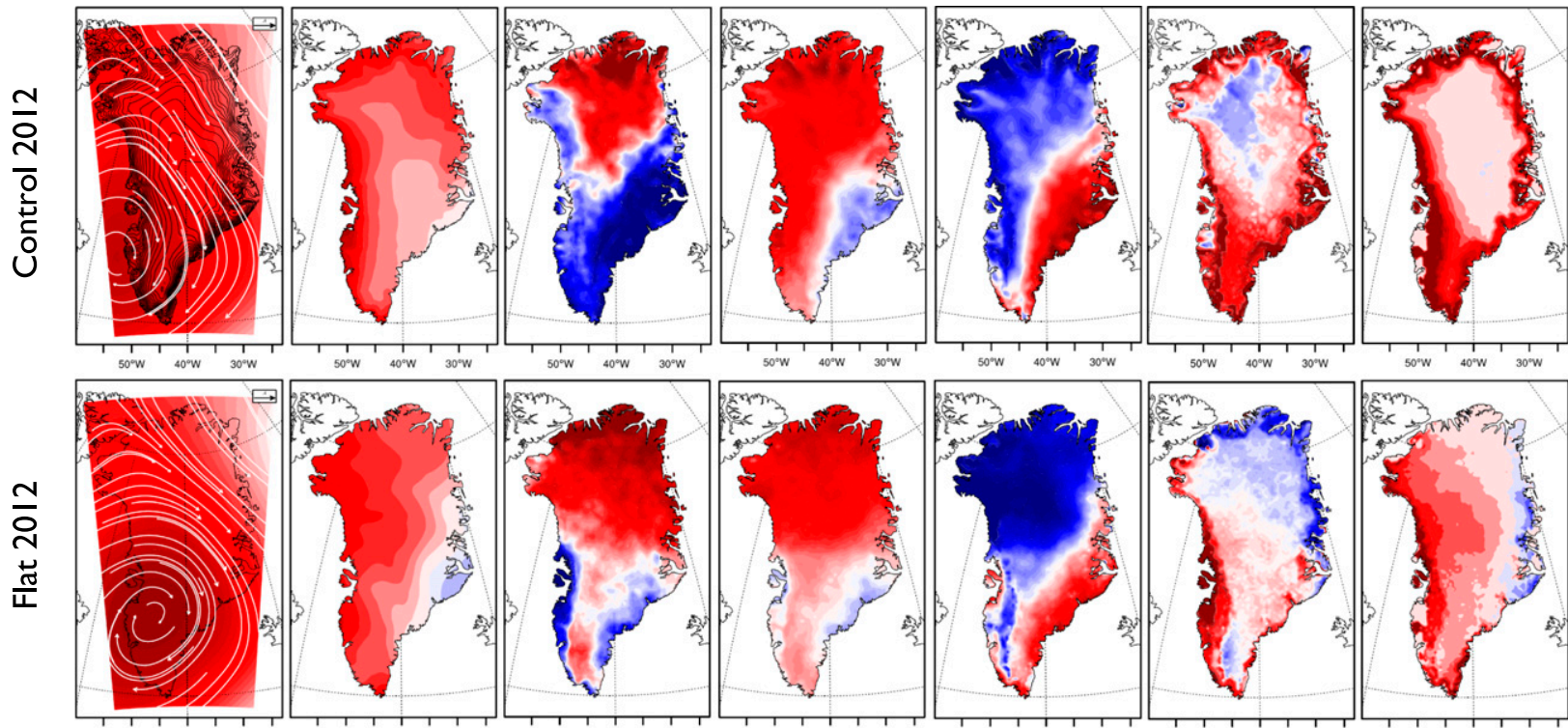

${ }_{50}^{1} \mathrm{~W}{ }_{40}^{\circ} \mathrm{W}{ }_{30}^{\circ} \mathrm{W}$

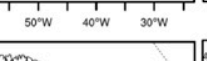

${ }_{50}^{\circ} \mathrm{W} \quad 0_{0}^{\circ} \mathrm{W} \quad 0_{30}^{\circ} \mathrm{W}$
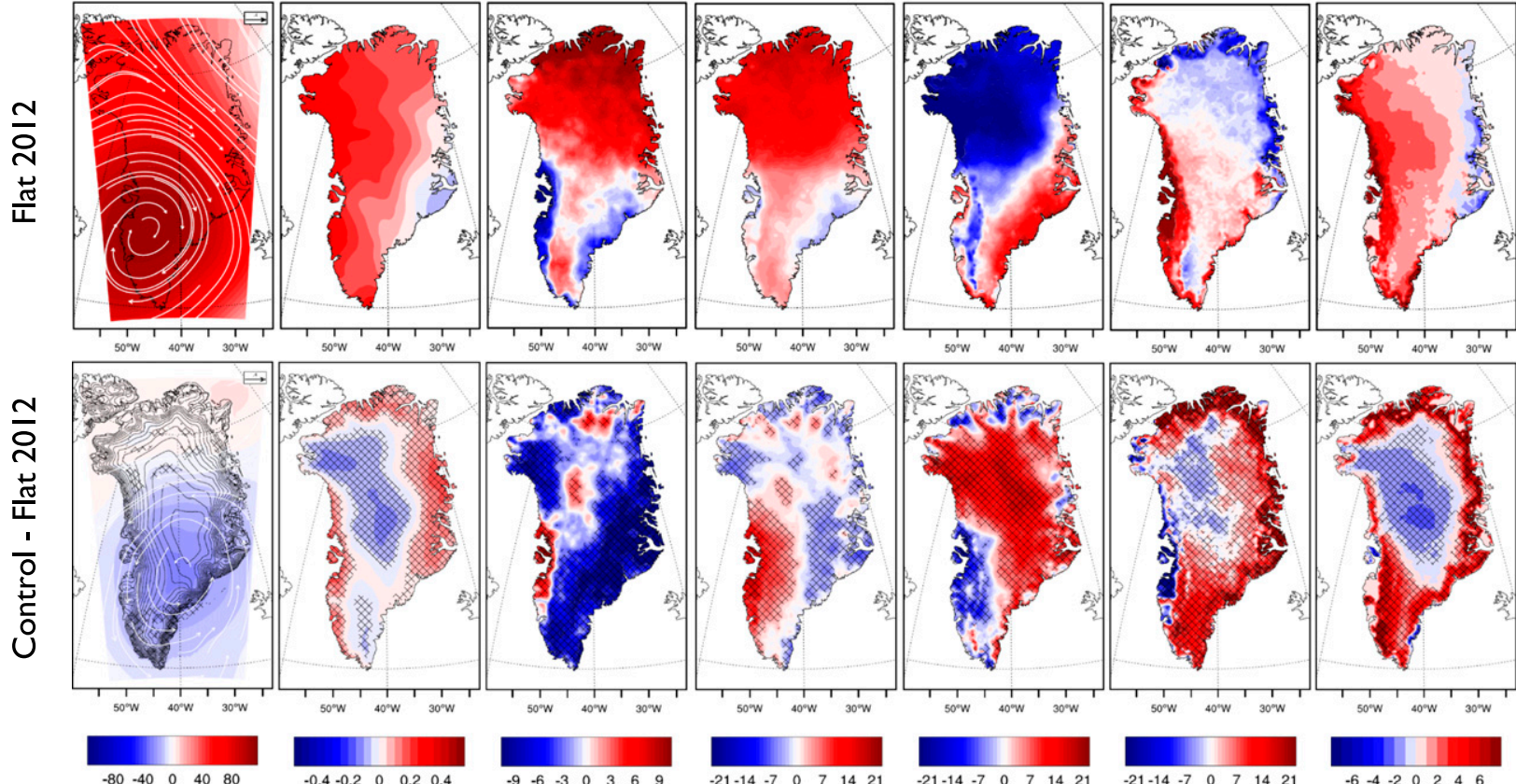

FIG. 12. JJA anomalies for 2012 compared to 1980-2017 period for (top) control and (middle) flat MAR simulations, and (bottom) the difference between control and flat anomalies for summer 2012, for (a) UV500 ( $\mathrm{m} \mathrm{s}^{-1}$ ) and Z500 (m); (b) water vapor path (WVP; $\mathrm{kg} \mathrm{m}^{-2}$ ); (c) cloud cover (CC; \%); (d) LWD $\left(\mathrm{W} \mathrm{m}^{-2}\right)$; (e) SWD $\left(\mathrm{W} \mathrm{m}^{-2}\right)$; (f) SWnet $\left(\mathrm{W} \mathrm{m}^{-2}\right)$; and (g) melt (mmWE day $\left.{ }^{-1}\right) .2012 \mathrm{MAR}^{-}$ surface height is shown in (a) for control simulation with contours from 0 to 3000 by $200 \mathrm{~m}$, while surface height is $0 \mathrm{~m}$ for the flat simulation. Stippling in bottom row indicates anomalies significant at the $95 \%$ confidence level for (a) all control compared with all flat summers and (b)-(g) control - flat difference for summer 2012 compared to 1980-2017.

thickness under greenhouse forcing include mass loss over the margins of the ice sheet, partly balanced by thickening of the interior ice sheet (Fürst et al. 2015). The resulting strengthening of surface height gradients may enhance orographic descent, reduce cloud cover, and increase shortwave radiation over southern Greenland under blocking conditions, although simultaneously increased water vapor path may instead promote increased cloud cover. Continued study of the mechanisms linking atmospheric circulation patterns with cloud and melt changes will improve predictions of melt forced both by climate change and internal variability.
Acknowledgments. This research was supported by the Woods Hole Oceanographic Institution Summer Student Fellow program, by the U.S. National Science Foundation under AGS-1355339 to C.C.U., and by the European Research Council through Grant 758005. We thank three anonymous reviewers for constructive feedback, which helped improve this study. Use of the following datasets is gratefully acknowledged: ERAInterim data provided by the European Centre for Medium-Range Weather Forecasts Data Archive, CERES data provided at https://ceres.larc.nasa.gov/index.php, and MAR data provided at ftp://ftp.climato.be/fettweis/ MARv3.5.2. The latest source code for the MAR model 
a) LWP
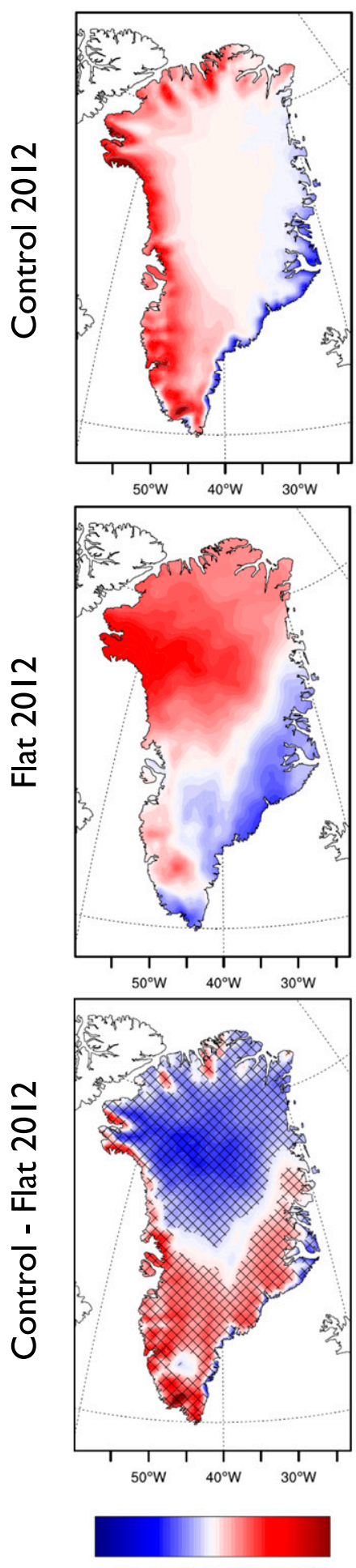

$\begin{array}{lllllll}-12 & -8 & -4 & 0 & 4 & 8 & 12\end{array}$ b) IWP
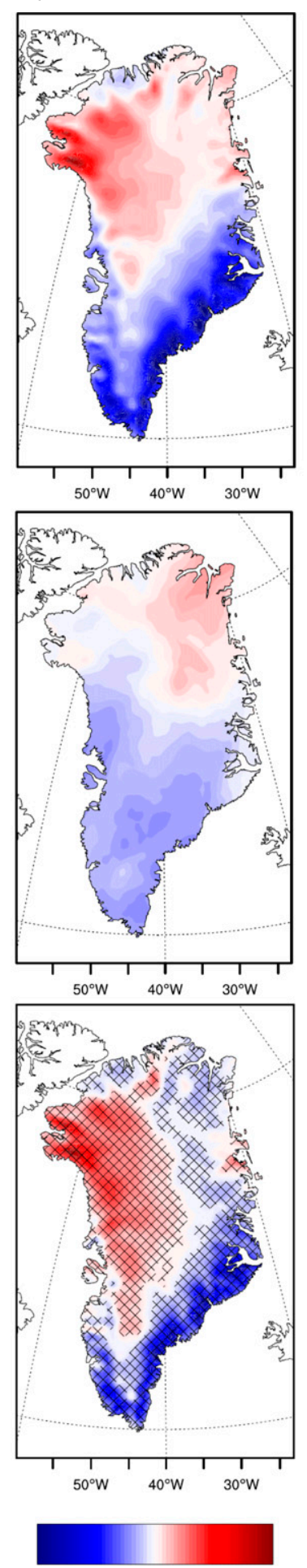

$\begin{array}{lllllll}-12 & -8 & -4 & 0 & 4 & 8 & 12\end{array}$ c) SHF
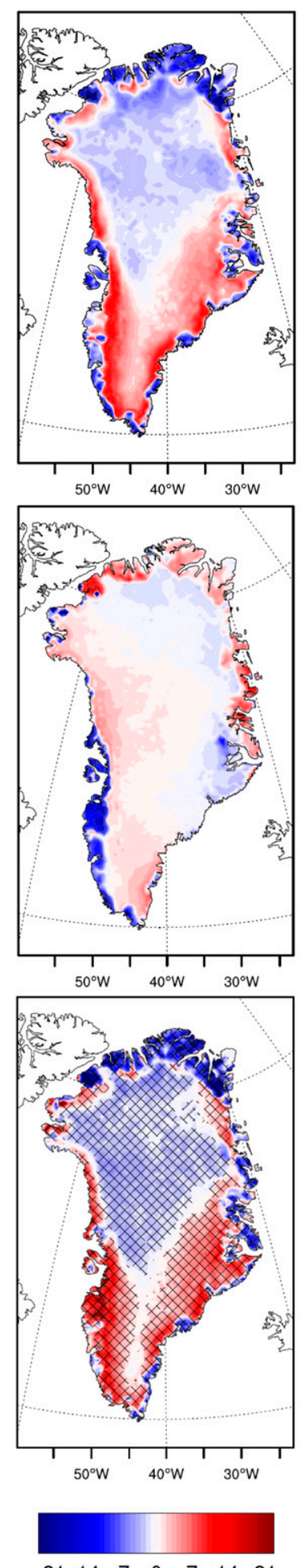

d) Albedo
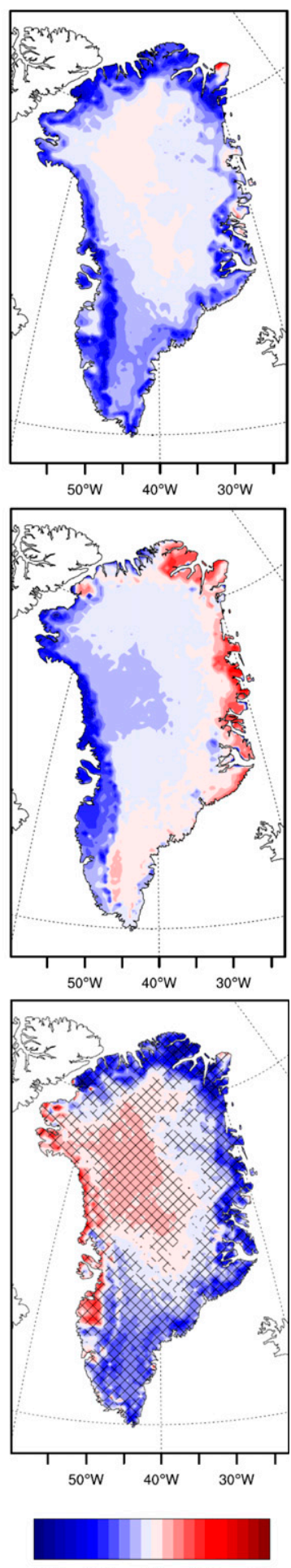

FIG. 13. JJA anomalies for 2012 compared to 1980-2017 period for the (top) control and (middle) flat MAR simulations, and (bottom) the difference between control and flat anomalies for summer 2012, for (a) liquid water path (LWP; $\mathrm{g} \mathrm{m}^{-2}$ ), (b) ice water path (IWP; $\mathrm{g} \mathrm{m}^{-2}$ ), (c) sensible heat flux (SHF; $\mathrm{W} \mathrm{m}^{-2}$ ), and (d) surface albedo. Stippling in the bottom row indicates anomalies significant at the $95 \%$ confidence level for the control - flat difference for summer 2012 compared to 1980-2017. 
is available via the MAR homepage at http://mar.cnrs.fr/ index.php?option_smdi $=$ presentation $\&$ idm $=10$.

\section{REFERENCES}

Agosta, C., and Coauthors, 2019: Estimation of the Antarctic surface mass balance using the regional climate model MAR (19792015) and identification of dominant processes. Cryosphere, 13, 281-296, https://doi.org/10.5194/tc-13-281-2019.

Aschwanden, A., M. A. Fahnestock, M. Truffer, D. J. Brinkerhoff, R. Hock, C. Khroulev, R. Mottram, and S. A. Khan, 2019: Contribution of the Greenland Ice Sheet to sea level over the next millennium. Sci. Adv., 5, eaav9396, https://doi.org/10.1126/ sciadv.aav9396.

Bennartz, R., and Coauthors, 2013: July 2012 Greenland melt extent enhanced by low-level liquid clouds. Nature, 496, 83-86, https://doi.org/10.1038/nature12002.

Böning, C. W., E. Behrens, A. Biastoch, K. Getzla, and J. L. Bamber, 2016: Emerging impact of Greenland meltwater on deepwater formation in the North Atlantic Ocean. Nat. Geosci., 9, 523-527, https://doi.org/10.1038/ngeo2740.

Bonne, J.-L., and Coauthors, 2015: The summer 2012 Greenland heat wave: In situ and remote sensing observations of water vapor isotopic composition during an atmospheric river event. J. Geophys. Res. Atmos., 120, 2970-2989, https://doi.org/10.1002/ 2014JD022602.

Box, J. E., X. Fettweis, J. C. Stroeve, M. Tedesco, D. K. Hall, and K. Steffen, 2012: Greenland ice sheet albedo feedback: Thermodynamics and atmospheric drivers. Cryosphere, 6, 821839, https://doi.org/10.5194/tc-6-821-2012.

Brun, E., P. David, M. Sudul, and G. Brunot, 1992: A numerical model to simulate snowcover stratigraphy for operational avalanche forecasting. J. Glaciol., 38, 13-22, https://doi.org/ 10.1017/S0022143000009552.

Chen, Q.-S., D. H. Bromwich, and L. Bai, 1997: Precipitation over Greenland retrieved by a dynamic method and its relation to cyclonic activity. J. Climate, 10, 839-870, https://doi.org/10.1175/ 1520-0442(1997)010<0839:POGRBA > 2.0.CO;2.

Christensen, M. W., A. Behrangi, T. S. L'Ecuyer, N. B. Wood, M. D. Lebsock, and G. L. Stephens, 2016: Arctic observation and reanalysis integrated system: A new data product for validation and climate study. Bull. Amer. Meteor. Soc., 97, 907-916, https:// doi.org/10.1175/BAMS-D-14-00273.1.

Chylek, P., J. E. Box, and G. Lesins, 2004: Global warming and the Greenland ice sheet. Climatic Change, 63, 201-221, https:// doi.org/10.1023/B:CLIM.0000018509.74228.03.

Dee, D. P., and Coauthors, 2011: The ERA-Interim reanalysis: Configuration and performance of the data assimilation system. Quart. J. Roy. Meteor. Soc., 137, 553-597, https://doi.org/ 10.1002/qj.828.

Delhasse, A., X. Fettweis, C. Kittel, C. Amory, and C. Agosta, 2018: Brief communication: Impact of the recent atmospheric circulation change in summer on the future surface mass balance of the Greenland ice sheet. Cryosphere, 12, 3409-3418, https://doi.org/10.5194/tc-12-3409-2018.

De Ridder, K., and H. Gallée, 1998: Land surface-induced regional climate change in southern Israel. J. Appl. Meteor., 37, 14701485, https://doi.org/10.1175/1520-0450(1998)037<1470: LSIRCC $>2.0 . \mathrm{CO} ; 2$.

Dethloff, K., and Coauthors, 2004: The impact of Greenland's deglaciation on the Arctic circulation. Geophys. Res. Lett., 31, L19201, https://doi.org/10.1029/2004GL020714.
Ding, Q., J. M. Wallace, D. S. Battisti, E. J. Steig, A. J. E. Gallant, H.-J. Kim, and L. Geng, 2014: Tropical forcing of the recent rapid Arctic warming in northeastern Canada and Greenland. Nature, 509, 209-212, https://doi.org/10.1038/nature13260.

_ and Coauthors, 2017: Influence of high-latitude atmospheric circulation changes on summertime Arctic sea ice. Nat. Climate Change, 7, 289-295, https://doi.org/10.1038/nclimate3241.

Doyle, S., and Coauthors, 2015: Amplified melt and flow of the Greenland ice sheet driven by late-summer cyclonic rainfall. Nat. Geosci., 8, 647-653, https://doi.org/10.1038/ ngeo 2482 .

Edwards-Opperman, J., S. Cavallo, and D. D. Turner, 2018: The occurrence and properties of long-lived liquid-bearing clouds over the Greenland Ice Sheet and their relationship to the North Atlantic Oscillation. J. Appl. Meteor. Climatol., 57, 921935, https://doi.org/10.1175/JAMC-D-17-0230.1.

Fettweis, X., G. Mabille, M. Erpicum, S. Nicolay, and M. Van den Broeke, 2011a: The 1958-2009 Greenland ice sheet surface melt and the mid-tropospheric atmospheric circulation. Climate Dyn., 36, 139-159, https://doi.org/10.1007/s00382-0100772-8.

_- M. Tedesco, M. van den Broeke, and J. Ettema, 2011b: Melting trends over the Greenland ice sheet (1958-2009) from spaceborne microwave data and regional climate models. Cryosphere, 5, 359-375, https://doi.org/10.5194/tc5-359-2011.

— B. Franco, M. Tedesco, J. H. van Angelen, J. T. M. Lenaerts, M. R. van den Broeke, and H. Gallée, 2013a: Estimating the Greenland ice sheet surface mass balance contribution to future sea level rise using the regional atmospheric climate model MAR. Cryosphere, 7, 469-489, https://doi.org/10.5194/ tc-7-469-2013.

_ , E. Hanna, C. Lang, A. Belleflamme, M. Erpicum, and H. Gallée, 2013b: Important role of the mid-tropospheric atmospheric circulation in the recent surface melt increase over the Greenland ice sheet. Cryosphere, 7, 241-248, https:// doi.org/10.5194/tc-7-241-2013.

, and Coauthors, 2017: Reconstructions of the 1900-2015 Greenland ice sheet surface mass balance using the regional climate MAR model. Cryosphere, 11, 1015-1033, https:// doi.org/10.5194/tc-11-1015-2017.

Franco, B., X. Fettweis, and M. Erpicum, 2013: Future projections of the Greenland ice sheet energy balance driving the surface melt. Cryosphere, 7, 1-18, https://doi.org/10.5194/ tc-7-1-2013.

Fürst, J. J., H. Goelzer, and P. Huybrechts, 2015: Ice-dynamic projections of the Greenland ice sheet in response to atmospheric and oceanic warming. Cryosphere, 9, 1039-1062, https://doi.org/ 10.5194/tc-9-1039-2015.

Gallée, H., 1995: Simulation of the mesocyclonic activity in the Ross Sea, Antarctica. Mon. Wea. Rev., 123, 2051-2069, https://doi.org/ 10.1175/1520-0493(1995)123<2051:SOTMAI > 2.0.CO;2.

— meso- $\gamma$ primitive equation model: Katabatic winds simulation in the area of Terra Nova Bay, Antarctica. Mon. Wea. Rev., 122, 671-685, https://doi.org/10.1175/1520-0493(1994)122<0671: DOATDM $>2.0 . \mathrm{CO} ; 2$.

Hahn, L., C. C. Ummenhofer, and Y.-O. Kwon, 2018: North Atlantic natural variability modulates emergence of widespread Greenland melt in a warming climate. Geophys. Res. Lett., 45, 9171-9178, https://doi.org/10.1029/2018GL079682.

Hakuba, M. Z., D. Folini, M. Wild, and C. Schär, 2012: Impact of Greenland's topographic height on precipitation and snow 
accumulation in idealized simulations. J. Geophys. Res., 117, D09107, https://doi.org/10.1029/2011JD017052.

Hanna, E., J. M. Jones, J. Cappelen, S. H. Mernild, L. Wood, K. Steffen, and P. Huybrechts, 2013: The influence of North Atlantic atmospheric and oceanic forcing effects on 1900-2010 Greenland summer climate and ice melt/runoff. Int. J. Climatol., 33, 862-880, https://doi.org/10.1002/joc.3475.

- and Coauthors, 2014: Atmospheric and oceanic climate forcing of the exceptional Greenland ice sheet surface melt in summer 2012. Int. J. Climatol., 34, 1022-1037, https://doi.org/ 10.1002/joc. 3743 .

_ - T. E. Cropper, R. J. Hall, and J. Cappelen, 2016: Greenland blocking index 1851-2015: A regional climate change signal. Int. J. Climatol., 36, 4847-4861, https://doi.org/10.1002/ joc. 4673 .

—, X. Fettweis, and R. J. Hall, 2018: Brief communication: Recent changes in summer Greenland blocking captured by none of the CMIP5 models. Cryosphere, 12, 3287-3292, https:// doi.org/10.5194/tc-12-3287-2018.

Hofer, S., A. J. Tedstone, X. Fettweis, and J. L. Bamber, 2017: Decreasing cloud cover drives the recent mass loss on the Greenland ice sheet. Sci. Adv., 3, e1700584, https://doi.org/ 10.1126/sciadv.1700584.

,,--- and -2019 : Cloud microphysics and circulation anomalies control differences in future Greenland melt Nat. Climate Change, 9, 523-528, https://doi.org/10.1038/s41558019-0507-8

Hurrell, J. W., 1995: Decadal trends in the North Atlantic Oscillation: Regional temperatures and precipitation. Science, 269, 676-679, https://doi.org/10.1126/science.269.5224.676.

_ , Y. Kushnir, G. Ottersen, and M. Visbeck, 2003: An overview of the North Atlantic oscillation. The North Atlantic Oscillation: Climatic Significance and Environmental Impact, Geophys. Monogr., Vol. 134, Amer. Geophys. Union, 1-36.

Junge, M. M., R. Blender, K. Fraedrich, V. Gayler, U. Luksch, and F. Lunkeit, 2005: A world without Greenland: Impacts on the Northern Hemisphere winter circulation in low- and highresolution models. Climate Dyn., 24, 297-307, https://doi.org/ 10.1007/s00382-004-0501-2.

Kato, S., and Coauthors, 2018: Surface irradiances of edition 4.0 Clouds and the Earth's Radiant Energy System (CERES) Energy Balanced and Filled (EBAF) data product. J. Climate, 31, 4501-4527, https://doi.org/10.1175/JCLI-D-17-0523.1.

Kristjánsson, J. E., and H. McInnes, 1999: The impact of Greenland on cyclone evolution in the North Atlantic. Quart. J. Roy. Meteor. Soc., 125, 2819-2834, https://doi.org/10.1002/qj.49712556003.

— S. Thorsteinsson, and B. Rosting, 2009: Phase-locking of a rapidly developing extratropical cyclone by Greenland's orography. Quart. J. Roy. Meteor. Soc., 135, 1986-1998, https:// doi.org/10.1002/qj.497.

Lenaerts, J. T. M., K. Van Tricht, S. Lhermitte, and T. L'Ecuyer, 2017: Polar clouds and radiation in satellite observations, reanalyses, and climate models. Geophys. Res. Lett., 44, 33553364, https://doi.org/10.1002/2016GL072242.

Lim, Y.-K., S. D. Schubert, S. M. J. Nowicki, J. N. Lee, A. M. Molod, R. I. Cullather, B. Zhao, and I. Velicognaet, 2016: Atmospheric summer teleconnections and Greenland ice sheet surface mass variations: Insights from MERRA-2. Environ. Res. Lett., 11, 024002, https://doi.org/10.1088/1748-9326/11/2/024002.

Lindsay, R., M. Wensnahan, A. Schweiger, and J. Zhang, 2014: Evaluation of seven different atmospheric reanalysis products in the Arctic. J. Climate, 27, 2588-2606, https://doi.org/ 10.1175/JCLI-D-13-00014.1.
Liu, Y., and J. R. Key, 2016: Assessment of Arctic cloud cover anomalies in atmospheric reanalysis products using satellite data. J. Climate, 29, 6065-6083, https://doi.org/10.1175/JCLID-15-0861.1.

Loeb, N. G., and Coauthors, 2018: Clouds and the Earth's Radiant Energy System (CERES) Energy Balanced and Filled (EBAF) Top-of-Atmosphere (TOA) edition-4.0 data product. J. Climate, 31, 895-918, https://doi.org/10.1175/JCLI-D-17-0208.1.

Mattingly, K. S., C. A. Ramseyer, J. J. Rosen, T. L. Mote, and R. Muthyala, 2016: Increasing water vapor transport to the Greenland Ice Sheet revealed using self-organizing maps. Geophys. Res. Lett., 43, 9250-9258, https://doi.org/10.1002/ 2016 GL070424.

— T. L. Mote, and X. Fettweis, 2018: Atmospheric river impacts on Greenland Ice Sheet surface mass balance. J. Geophys. Res. Atmos., 123, 8538-8560, https://doi.org/10.1029/2018JD028714.

McLeod, J. T., and T. L. Mote, 2016: Linking interannual variability in extreme Greenland blocking episodes to the recent increase in summer melting across the Greenland ice sheet. Int. J. Climatol., 36, 1484-1499, https://doi.org/10.1002/joc.4440.

Merz, N., A. Born, C. C. Raible, H. Fischer, and T. F. Stocker, 2014a: Dependence of Eemian Greenland temperature reconstructions on the ice sheet topography. Climate Past, 10, 1221-1238, https://doi.org/10.5194/cp-10-1221-2014.

, G. Gfeller, A. Born, C. C. Raible, T. F. Stocker, and H. Fischer, 2014b: Influence of ice sheet topography on Greenland precipitation during the Eemian interglacial. J. Geophys. Res. Atmos., 119, 10 749-10 768, https://doi.org/10.1002/2014JD021940.

Miller, N. B., M. D. Shupe, C. J. Cox, V. P. Walden, D. D. Turner, and K. Steffen, 2015: Cloud radiative forcing at Summit, Greenland. J. Climate, 28, 6267-6280, https://doi.org/10.1175/ JCLI-D-15-0076.1.

Minnis, P., and Coauthors, 2011: CERES edition-2 cloud property retrievals using TRMM VIRS and Terra and Aqua MODIS data-Part I: Algorithms. IEEE Trans. Geosci. Remote Sens., 49, 4374-4400, https://doi.org/10.1109/TGRS.2011.2144601.

Neff, W., G. P. Compo, F. M. Ralph, and M. D. Shupe, 2014: Continental heat anomalies and the extreme melting of the Greenland ice surface in 2012 and 1889. J. Geophys. Res. Atmos., 119, 6520-6536, https://doi.org/10.1002/2014JD021470.

Oltmanns, M., J. Karstensen, and J. Fischer, 2018: Increased risk of a shutdown of ocean convection posed by warm North Atlantic summers. Nat. Climate Change, 8, 300-304, https:// doi.org/10.1038/s41558-018-0105-1.

Parfitt, R., A. Czaja, S. Minobe, and A. Kuwano-Yoshida, 2016: The atmospheric frontal response to SST perturbations in the Gulf Stream region. Geophys. Res. Lett., 43, 2299-2306, https:// doi.org/10.1002/2016GL067723.

- _ - and H. Seo, 2017: A simple diagnostic for the detection of atmospheric fronts. Geophys. Res. Lett., 44, 4351-4358, https://doi.org/10.1002/2017GL073662.

Petersen, G. N., J. E. Kristjánsson, and H. Ólafsson, 2004: Numerical simulations of Greenland's impact on the Northern Hemisphere winter circulation. Tellus, 56A, 102-111, https:// doi.org/10.3402/tellusa.v56i2.14400.

Rahmstorf, S., J. E. Box, G. Feulner, M. E. Mann, A. Robinson, S. Rutherford, and E. J. Schaffernicht, 2015: Exceptional twentieth-century slowdown in Atlantic Ocean overturning circulation. Nat. Climate Change, 5, 475-480, https://doi.org/ 10.1038/nclimate2554.

Rutan, D., F. G. Rose, M. Roman, N. Manalo-Smith, C. Schaaf, and T. Charlock, 2009: Development and assessment of broadband surface albedo from Clouds and the Earth's Radiant Energy 
System Clouds and Radiation Swath data product. J. Geophys. Res., 114, D08125, https://doi.org/10.1029/2008JD010669.

Schuenemann, K. C., J. J. Cassano, and J. Finnis, 2009: Synoptic forcing of precipitation over Greenland: Climatology for 1961-99. J. Hydrometeor., 10, 60-78, https://doi.org/10.1175/ 2008JHM1014.1.

Shepherd, A., and Coauthors, 2012: A reconciled estimate of icesheet mass balance. Science, 338, 1183-1189, https://doi.org/ 10.1126/science. 1228102 .

Shupe, M. D., and J. M. Intrieri, 2004: Cloud radiative forcing of the Arctic surface: The influence of cloud properties, surface albedo, and solar zenith angle. J. Climate, 17, 616-628, https:// doi.org/10.1175/1520-0442(2004)017<0616:CRFOTA >2.0.CO;2.

Tedesco, M., X. Fettweis, T. Mote, J. Wahr, P. Alexander, J. E. Box, and B. Wouters, 2013: Evidence and analysis of 2012 Greenland records from spaceborne observations, a regional climate model and reanalysis data. Cryosphere, 7, 615-630, https://doi.org/10.5194/tc-7-615-2013.

, T. Mote, X. Fettweis, E. Hanna, J. Jeyaratnam, J. F. Booth, R. Datta, and K. Briggs, 2016: Arctic cut-off high drives the poleward shift of a new Greenland melting record. Nat. Commun., 7, 11723, https://doi.org/10.1038/ncomms11723.
Tsukernik, M., D. N. Kindig, and M. C. Serreze, 2007: Characteristics of winter cyclone activity in the northern North Atlantic: Insights from observations and regional modeling. J. Geophys. Res., 112, D03101, https://doi.org/10.1029/2006JD007184.

Van den Broeke, M. R., C. J. P. P. Smeets, and R. S. W. van de Wal, 2011: The seasonal cycle and interannual variability of surface energy balance and melt in the ablation zone of the west Greenland ice sheet. Cryosphere, 5, 377-390, https://doi.org/ 10.5194/tc-5-377-2011.

Van Tricht, K., and Coauthors, 2016: Clouds enhance Greenland ice sheet meltwater runoff. Nat. Commun., 7, 10266, https:// doi.org/10.1038/ncomms10266.

Wang, W., C. S. Zender, and D. van As, 2018: Temporal characteristics of cloud radiative effects on the Greenland ice sheet: Discoveries from multiyear automatic weather station measurements. J. Geophys. Res. Atmos., 123, 11348-11 361, https:// doi.org/10.1029/2018JD028540.

,,,--- and N. B. Miller, 2019: Spatial distribution of melt season cloud radiative effects over Greenland: Evaluating satellite observations, reanalyses, and model simulations against in situ measurements. J. Geophys. Res. Atmos., 124, 57-71, https://doi.org/10.1029/2018JD028919. 